\title{
(1)
}

UNIVERSIDAD PERUANA DE CIENCIAS APLICADAS

FACULTAD DE PSICOLOGIA

PROGRAMA ACADÉMICO DE PSICOLOGÍA

\section{Actitudes hacia las TIC por docentes que usan herramientas tecnológicas de un colegio privado de Lima}

TESIS

Para optar el título profesional de Licenciado en Psicología

\author{
AUTOR \\ María Fernanda Zamora Rubatto (0000-0002-6876-028X) \\ ASESOR DE TESIS \\ Renato Peñaflor Guerra (0000-0003-3663-565X)
}

Lima, 28 de Noviembre de 2018 


\section{RESUMEN}

La presente investigación está enmarcada dentro de la metodología cualitativa. Tiene como objetivo describir las actitudes que tiene un grupo de profesores de un colegio privado de la ciudad de Lima frente a la Tecnología de la Información y Comunicación como herramienta educativa. Para ello, se entrevistó a siete docentes que participaron de manera voluntaria. Los resultados de la investigación son: dos actitudes generales cada una de ellas está conformada por categorías que en conjunto conforman la actitud general. Cada categoría ha sido analizada según las tres características de la actitud. En primer lugar se encontró una actitud positiva entre los participantes en utilizar la tecnología durante el dictado de clases, este tema principal está conformado por tres categorías que lo conforman: motivación para los alumnos, captar la atención de los alumnos y uso de las TIC en el proceso. En segundo lugar se halló la actitud de buena disposición hacia las TIC para elaborar las diapositivas, este tema principal también está conformado por tres categorías que lo componen: Material guía para el dictado, integración de información adicional y gestión de tiempo.

Palabras clave: Actitudes, Tecnologías de la Información y Comunicación. 


\begin{abstract}
This research is framed in the qualitative methodology. Its purpose is to describe the attitudes that a group of teachers of a private university in Lima, has toward language comprehension and production, facing the Information Technology and Communication as an educational tool. For that, seven teachers accepted voluntarily to be interviewed. The research results are: two general attitudes, each one of them is composed of categories that as a whole comprise the general attitude. Each category has been analyzed according to the three characteristics of the attitude. First, a positive attitude toward using the technology while teaching classes was found among the participants, this main theme is composed of three categories: student motivation, capturing the attention of the students, and the use of ICT in the process. Second, the good disposition toward ICT to prepare the slides was found, this main theme is also composed of three categories: teaching guide, integration of additional information, and time management.
\end{abstract}

Key words: Attitudes, Information and Communication Technology. 


\section{TABLA DE CONTENIDO}

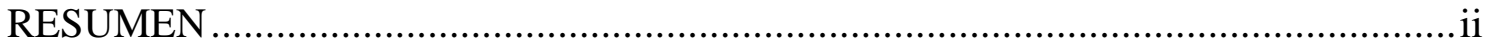

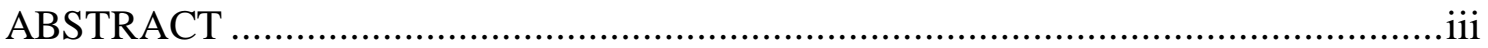

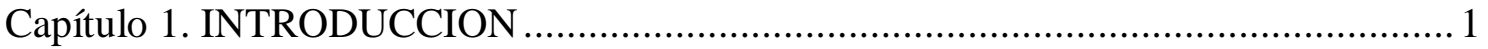

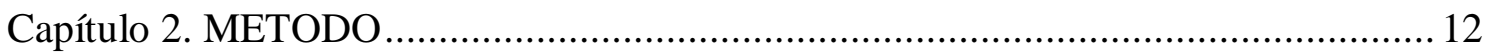

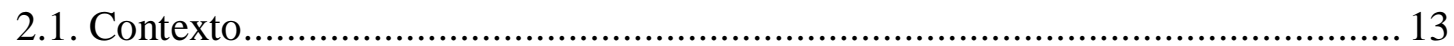

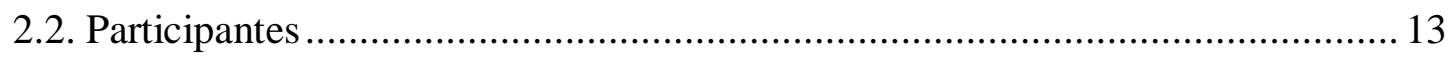

2.3. Técnica de recolección de información ......................................................... 15

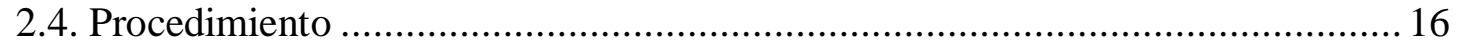

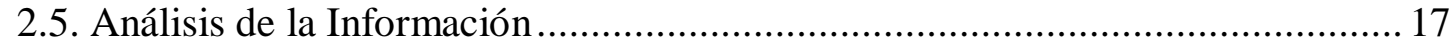

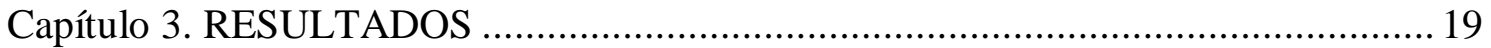

3.1. Actitud positiva en utilizar la tecnología durante el dictado de las clases .......... 20

3.2. Uso de las tic en el desarrollo de la clase ...................................................... 29

3.3. Buena disposición hacia las TIC para elaborar el dictado de clases ................... 31

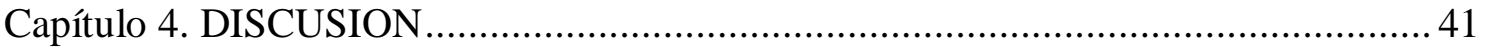

Capítulo 5. CONCLUSIONES Y RELEVANCIA .................................................... 46

Capítulo 6. LIMITACIONES Y RECOMENDACIONES ........................................ 49

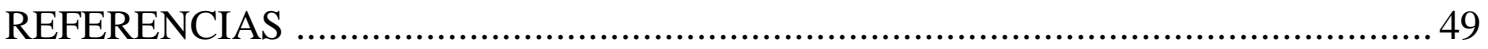

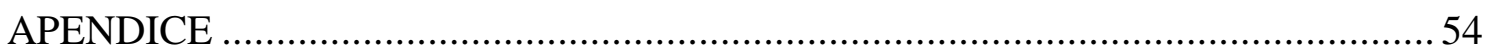




\section{INDICE DE TABLAS}

Tabla 1: temas y categorías 


\section{Capítulo 1. INTRODUCCION}

El uso de las Tecnologías de Información y Comunicación (TIC) se ha expandido en todos los ámbitos de la vida humana, generando en ellos un gran impacto (Aznar, Cáceres, \& Hinojo, 2005). El acceso cada vez más libre y rápido a internet y a plataformas virtuales permite una mayor interacción entre las personas, y como consecuencia de ello, los modelos de relación social y el contacto con la realidad van evolucionando (Aznar, Cáceres, \& Hinojo, 2005). Este fenómeno de la irrupción de la tecnología en la vida del ser humano incluye el ámbito educativo; así, tanto estudiantes como docentes acceden de forma distinta y con más velocidad a más información, modificándose significativamente el proceso de enseñanza-aprendizaje (López de la Madrid, 2007).

Así también en la actualidad existen diversos sitios y servicios web que facilitan la generación de redes sociales privadas y públicas con fines específicos, las cuales pueden aprovecharse por los docentes interesados. Estas redes sociales hoy en día acompañan la convivencia de las personas. De esta manera, se llama red social no sólo al grupo de personas, sino al sistema que las aloja y les brinda los servicios necesarios para logar interacciones (Valenzuela, 2013).

En el ámbito de la educación, la relevancia del uso de las TIC está relacionada con su utilidad para adquirir conocimientos y rutas de acceso que facilitan al estudiante adquirir nueva información. Los dispositivos electrónicos son capaces de recopilar, procesar y transferir información con mayor rapidez (López de la Madrid, 2007). En relación a los docentes, el uso de TIC abre oportunidades para que localicen información, se comuniquen y promuevan entre los alumnos un aprendizaje significativo (Montoro, Morales, \& Valenzuela, 2014). Entendiendo como uso de la tecnología a la acción de implementar las TIC como videos, herramientas didácticas en línea, programas que permitan la digitalización de la información por medio de dispositivos como computadora, laptops o celular en el salón de clases. Donde los promotores de estas actividades son los docentes quienes involucran al alumno en este proceso. Por su parte (Suárez, 29 de Junio de 2013) hace mención que el proceso en que las personas incorporan el uso de las tecnologías es una culturización digital por considerar la inclusión de los que 
no son "ciudadanos digitales", que se incorporan gradualmente a nuevos escenarios y dinámicas sociales.

Con todos los cambios dados en la educación por la implementación y el uso cotidiano de la tecnología los docentes tienen como objetivo preparar a los alumnos para este contexto donde las tecnologías son de uso cotidiano hasta el momento, esta adecuación se ha materializado en la creación de nuevas competencias básicas ligadas, a las TIC y la noción del aprendizaje a lo largo de la vida (Viñals \& Cuenca, 2016).

(López de la Madrid, 2007) menciona que hoy en día son los alumnos quienes buscan internarse en el mundo de la tecnología actualizándose constantemente, fuera y dentro del aula. Menciona, también que parece más complicado lograr que el docente tenga la misma actitud.

Es así como el docente se enfrenta a una nueva generación de alumnos con acceso a información rápida, sin censura y en volúmenes muy amplios, que ya no responden como antes a métodos de enseñanza tradicionales basados en la oralidad, el discurso y una cierta cantidad de imágenes o estímulos visuales estáticos. Esta realidad sitúa al docente frente a la necesidad de tomar una postura clara y concreta frente a la tecnología y buscar actualizaciones pedagógicas que le permitan adaptarse a los nuevos retos de la enseñanza. (Tello \& Aguaded, 2009).

El contexto actual ha influido en que los estudiantes se desarrollen en un ambiente tecnológico, por lo que el docente debe adecuarse a su forma de actuar y de concebir el aprendizaje. Es decir, el profesor tiene que digitalizarse y ser competente digital. Esta competencia está relacionada al uso de las tecnologías digitales lo cual implica ser una persona autónoma, eficaz, responsable, crítica y reflexiva al seleccionar, tratar y utilizar la información y sus fuentes, así como las distintas herramientas tecnológicas y al mismo tiempo demanda tener una actitud crítica y reflexiva en la valoración de la información disponible (Viñals \& Cuenca, 2016).

Los docentes se encuentran presionados por tres fuerzas contrapuestas. Por un lado, se les demanda que sean innovadores, autónomos y que desarrollen propuestas educativas flexibles que permitan articular distintos campos de conocimientos. En el contexto universitario, los alumnos generalmente jóvenes, utilizan el ipad, celulares y laptop, en todos los ámbitos de su vida incluyendo dentro de clases lo que puede ocasionar que su atención no este focalizada en la materia expuesta. Ante estas situaciones el docente universitario a empleado estrategias para compartir y transmitir la información utilizando para ello las TIC de forma adecuada y selectiva, en este caso el docente habrá 
preparado con anticipación apoyo visual y textual como fotografías, videos, notas, textos, herramientas de comunicación de calidad sobre el tema, siendo las guías para que ellos ingresen a información apropiada, creando una cultura visual y teórica (Durán \& Garces, 2015).

En el Perú, según la Ley General de Educación $\mathrm{N}^{\circ} 28044$, en su artículo $26^{\circ}$ referido a procesos pedagógicos, se menciona que los docentes deben integrar las TIC en su proceso de enseñanza, esto significa hacer uso de recursos y herramientas tecnológicas, cumpliendo con el uso efectivo del total de horas pedagógicas establecidas por el Decreto Supremo del Reglamento de Organización y Funciones, 006-2012-ED (2012).

El Ministerio de Educación ha mostrado cada vez un mayor interés en invertir en tecnología educativa a nivel escolar, desarrollando diversos proyectos como por ejemplo el proyecto "Huascarán” (Marcone, Castro, Kanashiro, Núñez del Prado, \& León, 2010). Este proyecto buscaba introducir las TIC en el sistema educativo rural, para mejorar su calidad (Ministerio de Educación, 2013). Es indispensable mencionar que el proyecto Huascarán fue una primera iniciativa.

En la actualidad la página web del MINEDU cuenta con materiales electrónicos llamados Rutas de Aprendizaje. Dichos archivos tienen diverso material para el docente escolar y uno de ellos es el documento: Usa la ciencia y la tecnología para mejorar la calidad de vida. Este archivo menciona la importancia de la ciencia y de la tecnología en el desarrollo integral de los alumnos y como la tecnología permite, mediante dispositivos electrónicos, transmitir la información utilizando materiales audiovisuales. Estos brindan diversas posibilidades de aprendizaje, debido a que permiten observar, manipular, consultar, medir, analizar, visualizar los ejercicios que se muestran también en sus libros (Ministerio de Educación, 2013).

Las universidades privadas también han apostado por las TIC. La Universidad Peruana de Ciencias Aplicadas, por ejemplo, ha invertido en la incorporación de tecnología de vanguardia en su infraestructura y procesos con el fin de crear una experiencia de aprendizaje novedosa para el alumno (Universidad Peruana de Ciencias Aplicadas, 2014). Así mismo, la Universidad Tecnología del Perú promueve la integración de la tecnología para una mejor enseñanza. Esta universidad se enfoca en fortalecer competencias digitales en docentes y alumnos, evaluar con una mirada prospectiva, prácticas pedagógicas innovadoras y desarrollar programas de formación a distancia o semipresenciales (b-learning) (Universidad Tecnológica del Perú (s/f)) 
La UNESCO (2004), menciona que las tecnologías de la información y la comunicación (TIC) son elementos considerables en la transformación de la nueva economía global y en los rápidos cambios que se están dando en la sociedad. Según (Romero, Saldívar, \& Delgado, 2011) "Las TIC son un conjunto de técnicas, desarrollos y dispositivos avanzados, que integran funcionalidades de almacenamiento, procedimiento y trasmisión de datos" (Párr. 1), siendo éstas una realización social que permite que los procesos de información y comunicación sean más sencillos. Por medio del desarrollo de la tecnología se da una construcción y extensión del conocimiento, que satisfacen las necesidades de los individuos de determinadas organizaciones sociales (Baelo \& Cantón, 2009).

El término TIC se deriva de tres palabras con significados aislados; tecnologías: "que es la aplicación de conocimientos científicos para facilitar la realización de actividades humanas" (párr. 4), información, que constituye "los datos que tienen significados para determinados colectivos" (párr. 5), y comunicación, como "la transmisión de mensajes entre personas" (párr. 5). Estas tres palabras, al unirse "hacen referencia al conjunto de avances tecnológicos que proporcionan la informática, telecomunicaciones”.... (Marquéz, 2000).

Las tecnologías de información y comunicación abarcan diversas herramientas virtuales. Las redes sociales son también parte de este grupo de herramientas. Gómez (2012), menciona que en el ámbito educativo éstas favorecen, tanto entre estudiantes en general, como entre estudiantes y profesores, la publicación de información, el trabajo en equipo, el aprendizaje autónomo, la comunicación, la retroalimentación, el acceso a otras redes afines y el contacto con otros expertos, entre otros. Ellas facilitan el aprendizaje constructivista y el aprendizaje colaborativo (Valenzuela, 2013).

El fenómeno de la expansión de las TIC en la vida del ser humano alcanza también el ámbito educativo, y genera un desafío para los docentes, que son en su mayoría inmigrantes digitales (Marchesi, 2012). El termino inmigrantes digitales hace referencia a personas que pertenecen a generaciones anteriores a los jóvenes y adolecentes de hoy en día, los cuales incluyeron la tecnología más tarde en sus vidas (Prensky, 2010) en este sentido la investigación se refiere a los docentes que a comparación de sus alumnos, estudiaron sin computadoras, internet, dispositivos electrónicos, ni herramientas en línea los cuales en la actualidad incluyen estos dispositivos en su trabajo.

La introducción de las TIC en las aulas implica la necesidad de una nueva conceptualización de roles para alumnos y docentes. En relación a los alumnos, éstos, al 
tener contacto con nuevas herramientas tecnológicas, pueden adquirir mayor autonomía y responsabilidad en el proceso de aprendizaje, obligando al docente a salir de su rol clásico como única fuente de conocimiento. La incertidumbre y el temor que muchas veces se presentan en los docentes, los conduce a vivir un proceso de readecuación creativa en la institución escolar (Lugo, 2010).

(Cabero \& Lorente, 2008) mencionan que una ventaja que ofrecen las TIC es la variedad de información que puede ser colgada de manera virtual para que los estudiantes tengan acceso a ella. Afirman que la situación actual es imparable, debido a que las páginas webs van creciendo de forma cuantitativa y cualitativa. Asimismo indican que con la utilización de las TIC, los alumnos y docentes pueden realizar actividades formativas y de interacción comunicativa independientemente del espacio y el tiempo en el que cada uno se sitúe, lo cual significa que a pesar de los límites espaciotemporales donde ambos se ubiquen es posible que exista intercambio de información.

En la investigación de (Povera \& Murillo, 2003) menciona las trasparencias o diapositivas para el dictado de curso de matemática, resaltan que ambas implica el manejo de algún programa, como PowerPoint de Microsoft. Si bien no es complicado su uso, si se requieren de saber de algunos elementos básicos en su producción. Se menciona también que el uso de la computadora es bastante más alto al igual que el de adquirir un proyector de video.

Según un estudio realizado en el 2013 por la Organización de Estados Iberoamericanos para la Educación, la Ciencia y la Cultura (OEI) llevado a cabo en Latinoamérica, el Perú ha incrementado el uso de la tecnología con fines educativos. Se calcula que hay ocho estudiantes por cada computadora y el $77 \%$ de escolares peruanos entre 10 y 18 años de edad usa recursos digitales para el estudio personal (El comercio, 2016).

Frente a estos nuevos cambios y al uso de las TIC, los docentes presentan diversas actitudes que requieren ser analizadas. Sin embargo, es necesario en primer lugar, conceptualizar el término "actitud".

Según Billig (1991), las actitudes de las personas evolucionan constantemente al estar en contacto con contextos y situaciones sociales cambiantes y diversas, por esta razón la actitud posee una estructura inacabada (citado en (Pacheco, 2002).

(Tejedor, Garcia Valcárcel, \& Prada, 2009) las actitudes son predisposiciones aprendidas que pueden variar y traen una carga valorativa hacia un objeto, que a su vez se traduce en una conducta hacia el mismo. 
Para la presente investigación se utiliza el concepto según el modelo metacognitivo. Desde este enfoque las actitudes hacia los objetos son evaluaciones positivas o negativas las cuales se encuentran en la memoria. Se mencionan tres características principales, la primera es la activación que depende del contexto en el que se encuentre la persona, si bien las actitudes están vinculadas en la memoria con una fuerza determinada su activación depende de diferentes factores contextuales. La segunda característica es que existen actitudes con valores antagónicos. La actitud que se recupera y utiliza está influenciada por factores como: la experiencia más reciente y del discriminar entre contextos donde la vinculación sea favorable según el contexto. Por último se encuentra la valoración que hace la persona de sus mismas valoraciones es decir la capacidad que tiene la persona para opinar sobre su propia valoración Petty, Biñol y DeMarre, 2007 (citado en de los Santos y Cantillo, 2012).

Para la presente investigación se comprende que las actitudes hacia las TIC, tomando en cuenta el modelo metacongnitivo, es la valoración que tiene el docente frente a una herramienta tecnología que le permite la interacción educativa con sus alumnos, la cual se presenta según las siguientes características: el contexto en el que se presenta el docente al momento de elaborar su material y de dictarla clase, la actitud que el docente presenta es determinada por la experiencia más reciente y donde éste valore un contexto favorable y la capacidad que presenta para opinar acerca de la valoración que le da a la herramienta.

Aclarado el concepto de actitud, se abordarán diversas investigaciones que analizan la actitud docente frente a las TIC.

En el año 2015, Mendoza, Enciso, Fonseca y Gonzáles, investigaron las actitudes que tienen los docentes de la Unidad Académica de Derecho de la Universidad Autónoma de Nayarit en México, bajo una metodología cuantitativa. En dicho estudio se da cuenta que existe una actitud positiva hacia las TIC. Los autores mencionan que los docentes presentan disposición para recibir capacitación, están convencidos que a mayor conocimiento es mayor la percepción sobre el uso. De igual manera, se aclara que los docentes perciben a la tecnología como necesaria, eficaz, agradable, flexible y ágil, pero aún hay un porcentaje considerable en que la ven como algo complicado.

En la investigación realizada por Cardona, Fandiño y Galindo (2014), donde el objetivo era explorar el impacto de un proceso formativo en TIC a través de wikis sobre las creencias, actitudes y competencias de un grupo de profesores de inglés en la cuidad de Colombia. Se obtuvo entre otros resultados una actitud favorable a utilizar tecnología 
en el salón de clase para mejorar los niveles de enseñanza y aprendizaje, y desarrollar actividades de mayor grado creativo. De esta manera afirman que existe una disposición positiva frente al uso educativo que el docente de lengua puede hacer de las TIC para fortalecer la enseñanza y el aprendizaje de contenidos más auténticos y significativos

La investigación por (García Arrea \& Chikhani, 2012) sobre las percepciones que tienen profesores de primaria y secundaria en América Latina acerca del uso de TIC en la educación, fue realizada a una muestra de docentes encuestados que tenían conocimiento básico en el uso de herramientas de computación. Los resultados mostraron que éstos piensan que las TIC hacen interesante el proceso de aprendizaje para los estudiantes, y sirven como recursos y apoyo para la producción intelectual. Los docentes consideraron que las TIC aportarían a una enseñanza más dinámica y moderna que involucra a su vez más al estudiante.

Asimismo, el estudio muestra que la tecnología hace el aprendizaje más agradable, y brinda más oportunidades de utilizar diversos métodos de enseñanza en el aula. Por medio de las TIC, los alumnos tienen un mayor acceso a recursos educativos y escenarios de aprendizaje que trascienden la tradicional clase lectiva en aula. Sin embargo, según los resultados, los docentes son conscientes de que la tecnología en sí, no asegura una educación de calidad.

Siguiendo con la investigación, ésta mostró que la compatibilidad con la tecnología aumenta si el docente se da cuenta de que es posible encontrar recursos ventajosos ahorrando tiempo y esfuerzo. Sin embargo, los participantes no consideran que las TIC sean útiles en todas las etapas del aprendizaje. Los autores mencionan que son los docentes quienes deben modernizar sus prácticas de enseñanza teniendo a las TIC como un recurso importante; señalan también que depende del estilo de cada profesor y de cómo éste maneje el conocimiento en las TIC para poder acceder a la tecnología (García Arrea \& Chikhani, 2012)

En la investigación de diseño mixto realizada en La mancha, España, por sobre (Sáez L. , 2010)cuyo objetivo de estudio fue conocer la valoración del uso y actitudes de los maestros de educación infantil y primaria respecto a las TIC en los contextos educativos. Los docentes muestran una concepción positiva de la aplicación de la tecnología dentro del salón de clases, lo consideran positivo por ser una práctica indagadora y reflexiva que les permite potenciar su uso en las actividades de aprendizaje. Para la mayoría de docentes las TIC mejoran la calidad de la enseñanza, los maestros consideran valioso y beneficioso el uso de las tecnologías en la práctica educativa. En 
definitiva, un 59,4\% de la muestra considera importante y beneficiosa la formación de los docentes para el uso de las tecnologías.

En el ámbito nacional se encuentra la investigación realizada por (Flores, 2012), la cual tenía como propósito conocer la actitud hacia las tecnologías de información y comunicación de los docentes de la Red Educativa No 01 de Ventanilla - Callao. En los resultados se destacan que la mayoría manifiestan actitudes cognitivas favorables con un $(63,6 \%)$ hacia las tecnologías de información y comunicación, mientras que un 17,3\% un medianamente favorables y actitudes desfavorables $(19,1 \%)$.

Dentro del mismo ámbito nacional no se han realizado investigaciones cualitativas sobre estudios que describan las actitudes que tiene el docente escolar frente a la tecnología como una herramienta educativa. En el ámbito internacional, se puede acceder a literatura sobre las actitudes frente a las TIC por parte de docentes escolares o universitarios en su mayoría de enfoque mixto o cuantitativo.

La investigación de (Chumpitaz| \& Rivero, 2012) sobre el uso cotidiano y pedagógico de la TIC por profesores en una Universidad de Lima, encontró que el 94,7\% de los encuestados utilizan herramientas tecnológicas en sus clases. Sin embargo, en la universidad en la que se realizó esta investigación no existen investigaciones previas sobre el uso que tienen los docentes de la tecnología de vanguardia que se utiliza en la institución.

Existe una brecha de valoración, disposición y capacidad para usar la TIC entre los alumnos de las actuales generaciones y sus docentes. Estos últimos, al pertenecer en su mayoría a una generación que ha migrado a la tecnología, no llegan a insertarse con facilidad en el mundo de las TIC a comparación de los alumnos. Por ello, la educación superior tiene la necesidad de enfocarse no solo en la formación de profesionales, sino principalmente en la generación de nuevos conocimientos, que respondan a demandas de la sociedad a corto, mediano y largo plazo (Romero R. T., 2004) y para ello, deben preocuparse por sensibilizar y capacitar a sus docentes.

Para un correcto acceso a las Tecnologías de la información y la comunicación es necesario contar con una serie de recursos o materiales que requieren en algunos casos un mantenimiento y un servicio técnico. En esta línea, es evidente que, para que un centro de estudios universitarios pueda insertar las TIC en el trabajo en aula de sus docentes y en la gestión pedagógica general, debe contar con los recursos económicos y técnicos para dotar sus espacios con equipos, materiales, dándoles el debido mantenimiento. Solo 
así, podrá posibilitar un diseño curricular pedagógico y el desarrollo de actividades en todas las áreas a través de las tecnologías (Sáez L. J., 2010).

Se puede decir en base a las investigaciones ya mencionadas en líneas anteriores que la introducción de las TIC en el ámbito educativo modifica el proceso de enseñanza y aprendizaje viéndose involucrados alumnos y docentes. Sin embargo, no sólo las actitudes hacia las TIC son aspectos importantes de los docentes, sino también que la institución educativa tenga los recursos tecnológicos necesarios. En las siguientes líneas se compartirán investigaciones referentes al uso de las TIC por docentes, y se analizará la importancia que le dan al tema en algunos países de habla hispana.

En la investigación de Parra y Chávez (2016) en la ciudad de México sobre el uso de redes sociales para fines académicos, uno de sus objetivos fue conocer el porcentaje de estudiantes y docentes de la Extensión Académica del Norte que hacen uso de las redes sociales. La investigación dio como resultado que el $97.44 \%$ de los docentes tienen acceso a las redes sociales todos los días siendo el Facebook la red más popular entre los docentes. La razón principal por la que los docentes crearon un perfil en redes sociales era para mantener comunicación con amigos y familiares, seguida por la de enviar información académica y crear un grupo de estudio. En relación al contenido que comparten con sus alumnos a través de internet todos comparten información académica, el $20 \%$ además de comparte videos y fotografías, el $15 \%$ publicaciones o estados y el $5 \%$ otro tipo de información como convocatorias de becas y frases de motivación.

En un estudio realizado por (Almerich, Suárez, \& Jornet, 2011), sobre las competencias que posee el profesorado de Educación Primaria y Secundaria de la Comunidad sus resultados indican distintos niveles de conocimiento e integración de las TIC entre el profesorado, el conocimiento de los recursos tecnológicos es un poco más alto que el nivel de integración habitual de éstos en el salón de clase. Así también el uso de los recursos tecnológicos por parte de los maestros es bajo, para uso personal profesional, y especialmente en el salón de clases. Por otra parte, los resultados arrojaron que el maestro de menor edad tiene un mayor nivel de competencias y uso de las TIC.

El profesorado situado entre 36-46 años muestra una mayor implicación hacia las competencias pedagógicas y el uso de las TIC con el alumnado. Los mayores de 46 años son los que menor dominio y uso de los recursos tecnológicos poseen (Almerich, Suárez, \& Jornet, 2011, pág. 37).

Siguiendo con la investigación de (Almerich, Suárez, \& Jornet, 2011) el nivel de competencia y el uso de las TIC se incrementan según el profesorado aumenta la 
frecuencia de uso del ordenador, las competencias tecnológicas y el uso personal profesional. Se podría deducir que hay una correlación entre el uso de TIC en el ámbito personal y el profesional, pero no necesariamente que un mayor uso en uno de los ámbitos acrecienta el uso en el otro.

En la referida investigación de (García Arrea \& Chikhani, 2012) se menciona que los docentes tienden a pensar que aprender a usar las TIC es más sencillo que emplearlas en sus sesiones de clase. Los autores afirman que, en la medida que los docentes piensan que el uso de las TIC requiere un mayor esfuerzo y dedicación, abandonan su uso de manera más rápida.

En la investigación con docentes ecuatorianos, (Salomé, 2010) obtuvo como resultado que la mayoría no utilizó las TIC en sus sesiones de clases y aunque el 18\% dice estar de acuerdo con su incorporación, es la minoría la que puede tener acceso a estos medios.

Por otro lado, en relación a la investigación en México de Alvarez (2004) acerca del uso de la tecnología educativa en docentes universitarios de la UDLA, encontró que el $47 \%$ de los docentes utilizaron constantemente diversas tecnologías al dictar sus cursos, siendo la computadora el elemento más utilizado con un $87.74 \%$ por profesores a tiempo parcial y de $98 \%$ por profesores a tiempo completo.

En el ámbito nacional, la investigación realizada por (Chumpitaz| \& Rivero, 2012) en universidades de Lima encontró que la mayoría de docentes (94,7\%) utiliza herramientas tecnológicas en clase. Sin embargo, menos de la mitad (45\%) las usa todos los días como parte de la preparación y el dictado. En relación al tipo de tecnología empleada en el aula "el 93,5\% usa una computadora, el 83,5\% internet y el 69,5\% videos" (p. 91, párr.2). Finalmente, la investigación menciona que el 62,78\% de los docentes está de acuerdo en realizar acciones y estrategias utilizando principalmente la tecnología para sus clases.

Después de lo expuesto, se debe resaltar que la presente investigación tiene como objetivo describir las actitudes que tiene un grupo de docentes escolares peruanos frente a la tecnología de la información como herramienta educativa. En la actualidad no se encuentran investigaciones como la presente, la cual describe actitudes frente a herramientas tecnológicas, las cuales se implementan cada día más en el ámbito de la educación. La metodología que se eligió para la investigación, permite tener un mejor acercamiento a los participantes para poder recaudar mayor información y entender sus actitudes. Los resultados pueden ser beneficiosos primero para enriquecer el debate sobre 
el tema a nivel nacional, pero también al momento de seleccionar y capacitar profesores escolares o planificar estrategias que motiven el uso de la tecnología en la plana docente.

En base a lo explicado anteriormente, la pregunta que se busca responder es iqué actitudes presentan los docentes de educación básica regular hacia el uso de herramientas tecnológicas en el dictado de clases? 


\section{Capítulo 2. METODO}

La presente investigación se enmarca dentro de un enfoque cualitativo, que indaga en las experiencias de los sujetos en su vida cotidiana (Mayan, 2001). Se conoce como investigación naturalista, porque se utiliza para comprender con naturalidad los hechos que ocurren. En este sentido, el escenario de la investigación no es manipulable por el investigador. Se trata de buscar información analizando y desplegando la vida cotidiana del entrevistado (Mayan, 2001).

De esta manera, la investigación cualitativa trata de identificar la naturaleza profunda de las realidades, su estructura dinámica que es aquella que da razón de su comportamiento (Martínez M. , 2006). Se eligió también la metodología fenomenológica que, para Mertens (2005) se enfoca en las experiencias individuales subjetivas de los participantes. De acuerdo con Creswell Álvarez-Gayou y Mertens, el diseño fenomenológico se basa en el análisis de discursos y temas específicos, así como en la búsqueda de sus posibles significados (citado en (Hernández, Fernández, \& Baptista, 2010).

El proceso de la investigación y el informe escrito se desarrolló cuidadosamente, para garantizar la calidad del estudio. Es importante mencionar que existen criterios dependientes para juzgar la calidad de la investigación y no solo un criterio aislado (Mendizábal, 2006). Los criterios redefinidos por Guba y Lincoln (como se citó en (Mendizábal, 2006) son: credibilidad, transferibilidad, seguridad y confiabilidad.

La credibilidad implica el compromiso con el trabajo, el cual fue realizado de manera responsable, escuchando de manera activa a los participantes, realizando las transcripciones literales de los audios. Así mismo, se obtuvo datos ricos y complejos, información detallada que permitió una mayor comprensión del tema (Mendizábal, 2006). La triangulación es una estrategia sugerida y utilizada para aumentar la confianza de los datos (Mendizábal, 2006). Según Denzin (como se citó en (Cornejo \& Salas, 2011), la triangulación se puede realizar partiendo de la contraposición y comparación constante de distintas miradas hacia el objeto de estudio. De esta manera, es posible también utilizar fuentes teóricas. Esta metodología se plasmó también en la discusión de resultados, incluyendo información teórica para la interpretación de los mismos. 
La transferibilidad, se refiere al alcance del conocimiento logrado en la investigación, y si se puede o no generalizar sus hallazgos hacia un contexto más amplio, partiendo de un resultado en un grupo particular. Se menciona que dentro de la investigación cualitativa una validez externa no es posible ni es un objetivo del método cualitativo; sin embargo se plantea la posibilidad de transferir los resultados de un contexto particular a otro con un contexto similar (Mendizábal, 2006). Para este caso concreto, esta investigación generaliza sus resultados solo para los docentes de básica regular de un colegio particular.

El criterio de seguridad, se deriva del término confiabilidad, y tiene como propósito el garantizar la seguridad de los procedimientos para la obtención de datos, utilizando pautas de escritura, registros textuales de datos, diferencia entre los testimonios y las interpretaciones del investigador (Mendizábal, 2006). En el caso de esta investigación se realizó un registro textual de los datos recogidos, lo que permitió la veracidad de la información. Así mismo, existió diferencia entre los testimonios y las interpretaciones de la investigadora.

\subsection{Contexto}

La presente investigación se realizó en un colegio particular. Este centro educativo alberga estudiantes de nivel socioeconómico bajo, los cuales provienen de la zona de Ate.

En relación al centro educativo, éste cuenta con aulas equipadas con écran y pizarra acrílica, las laptops que se utilizan en las aulas se encuentran en secretaria y son pedidas por los docentes, algunos de ellos cuentan con sus propias laptops.

La institución educativa tiene 10 años de funcionamiento y hace 4 años implementaron la tecnología en los salones de clases.

\subsection{Participantes}

Serán parte de la investigación aquellos que cumplan con los siguientes criterios de inclusión: ser profesores que dicten las áreas propuesta por el ministerio de educación de primaria y secundaria en el 2016 los cuales son: Área de Personal Social, Área de comunicación, Área de Matemáticas, Área de Ciencia y Tecnología, Área de Educación

Religiosa, Área de inglés área de psicomotriz, Área de descubriendo del mundo, Área de 
educación para el trabajo, Área de arte y cultura. Solo se tomarán en cuenta áreas donde la evaluación de desempeño es escrita y donde del docente tiene la oportunidad de desarrollar capacidades en sus alumnos con el uso de materiales que están relacionados al empleo a la tecnología.

Como criterios de exclusión, no serán parte de la investigación aquellos docentes que no utilizan dentro del contexto educativo herramientas tecnológicas para el dictado de las clases y aquellos que expresaron su deseo de no hacerlo.

De esta manera, la investigación cuenta con una muestra cualitativa intencional, (Pérez, Lagos, Mardones, \& Sáez, 2018) mencionan que el muestreo intencionado es el que se realiza tomando en cuenta los criterios preestablecidos por el investigador, guiados por la teoría sobre el problema. En el caso de la presente investigación se eligen los cursos mencionados anteriormente porque son aquellos en donde del docente tiene la oportunidad de desarrollar capacidades en sus alumnos con el uso de materiales que están relacionados al empleo a la tecnología.

Para (Serbia, 2007) en la etapa inicial de la investigación la decisión muestral puede estar orientada por criterios que dependerán de las características particulares de cada estudio, de esta manera la representatividad de la muestra no radica en la cantidad de las mismas, sino en las posibles configuraciones subjetivas de los participantes con respecto a un objeto o fenómeno determinado. Es importante aclarar que en el colegio solo existe un profesor de sexo masculino que enseña dentro de los cursos establecidos para la investigación, siendo la característica particular de este estudio el investigar a docentes con las características mencionadas anteriormente, no es necesario que exista la misma cantidad de hombres y de mujeres, ya que no es un aspecto que se tome en cuenta para realizar el objetivo planteado.

Por otra parte, (Martínez S. , 2012) denomina que la elección propositiva o de juicio, no parte de un número determinado de antemano. Menciona que en la investigación cualitativa no existen reglas para decidir el tamaño de la muestra y, si hubiera que enunciar alguna, está sería: “todo depende” (Martínez S. , 2012, pág. 4). De esta manera para poder juzgar si una muestra es adecuada hay que conocer el contexto del estudio.

El total de docentes en la institución fue de 13 profesores en total, aquellos profesores que cumplían con dictar las áreas mencionadas fueron 9 profesores, de los cuales 7 decidieron participar de manera voluntaria en el la investigación. A esta clase de muestra se le llama autoseleccionada, ya que las personas se proponen como participantes 
en el estudio o responden activamente a una invitación (Hernández, Fernández, \& Baptista, 2010).

Siendo el objetivo de la presente investigación describir las actitudes que tiene este grupo de 7 docentes frente a la tecnología de la información como herramienta educativa. Se considera suficiente estos participantes.

\subsection{Técnica de recolección de información}

Como instrumento de recolección de información, se utilizó la entrevista de investigación, instrumento que permite al investigador profundizar sobre los temas tratados (Martínez M. , 2006). Se eligió este tipo de instrumento, debido a que su propósito es obtener descripciones del mundo vivido por los participantes, con el fin de lograr interpretaciones manifiestas del significado que tienen los fenómenos descritos (Kavale, como se citó en (Martínez M. , 2006).

Así, la presente investigación utiliza la entrevista semiestructurada, según Bernard (citado en (Tarrés, 2001) caracterizada por mantener una conversación sobre un tema en particular contando con preguntas o temas ya establecidos, los cuales permiten al entrevistado tener libertad suficiente para definir el contenido de la discusión dependiendo de la naturaleza de la entrevista. Sin embargo, se utilizó una guía que permitía a la entrevistadora tomar en cuenta los temas que se estaban tocando.

Al principio de la investigación se planteó una entrevista estructurada, y para ello se realizó un listado de preguntas según los temas a investigar. Sin embargo, conforme se realizaron los pilotos, se vio necesario utilizar otro concepto de actitud que vaya más acorde con la naturaleza de la investigación, por lo cual estructura de la entrevista vario. Finalmente, se concluyó que para la investigación se utilizaría la entrevista no estructurada, en donde el papel del entrevistador es desempeñar un rol de receptor pasivo, manteniendo pausas adecuadas e intervenir en lo esencial para orientar la conversación al tema de interés (Tarrés, 2001).

Para la realización de la entrevista se tomó dos temas importantes en los que gira la entrevista: el material tecnológico utilizado en clases y la elaboración de las diapositivas. Así mismo, fue importante tener en cuenta las tres características de las actitudes, las cuales responden a la teoría; las preguntas han sido elaboradas para permitir profundizar en ellas. 
Los temas en los que la entrevista se desarrolló fueron revisados por expertos sobre el tema a tratar, quienes constataron que la guía estaba dirigida para mantener una conversación utilizando preguntas que facilitaban la recolección de los datos esperados. Los instrumentos utilizados se encuentran al final del estudio, en la sección Apéndice 2.

\subsection{Procedimiento}

El primer paso para poder conversar con los docentes fue contactar al director del colegio. Luego de algunas reuniones donde se explicó la investigación, el director dio el permiso para la aplicación de las entrevistas a docentes.

Posteriormente se elaboró una guía con preguntas estructuradas, la cual fue revisada por expertos. En base a la guía se elaboraron dos entrevistas piloto que se grabaron y transcribieron. Como se mencionó líneas arriba, al revisar los resultados de las entrevistas, se replanteó la forma de entrevistar, enfocándola hacia una conversación guiada en base a preguntas que podían cambiar según el docente y la situación, lo que permitía una entrevista no estructurada. Esta reestructuración se realizó con el apoyo del asesor de la investigación para luego pasar por revisión de expertos, los cuales opinaron y aprobaron los cambios de la reformulación de la entrevista. De esta manera se elaboró una guía para realizar una entrevista semiestructurada. La cual fue empleada en un tercer piloto con las modificaciones realizadas, notando una diferencia positiva en la entrevista.

A continuación, se buscó a los docentes personalmente para agendar la entrevista en su tiempo libre. Las entrevistas se desarrollaron dentro del colegio en un salón o la sala de profesores, ambientes donde solo estaba el entrevistado y la entrevistadora. Las conversaciones se iniciaron con una pregunta general sobre el impacto de la tecnología en el curso.

Se entrevistó a 7 docentes que tienen entre 23 a 46 años de edad 6 mujeres y un varón. A cada uno se le colocó un seudónimo para proteger su identidad. El número de participantes son todos aquellos que decidieron participar voluntariamente en la investigación y que cumplieron con criterios de inclusión.

Finalizadas las entrevistas, los audios grabados fueron transcritos para poder realizar el análisis de la información. 


\subsection{Análisis de la Información}

Para el análisis de la información se utilizó el análisis temático. (Braun \& Clarke, 2006) mencionan que este tipo de análisis es una herramienta cualitativa que sirve para identificar patrones, analizar y presentar temas dentro de la información recolectada. Se caracteriza por generar códigos iniciales, los cuales posteriormente se pueden invertir en temas según la similitud y relevancia del contenido de la información, el análisis implica ir y volver sobre la información obtenida.

Por otro lado, se puede acompañar el análisis acudiendo a literatura sobre el tema, revisando qué dice la teoría sobre los patrones que se van encontrando (Braun \& Clarke, 2006).

Para realizar el análisis temático, (Braun \& Clarke, 2006) mencionan que se cuenta con diferentes fases. En la fase uno se encuentra la familiarización con la data recolectada. Ésta consta de la lectura y la relectura de la data recolectada. Si la data es recolectada en audios, éstos deben de transcribirse rigurosamente. La fase dos consta de generar códigos iniciales partir de la información obtenida, en donde la data es organizada por agrupaciones con sentido. ¿Codificado contenidos? interesantes de manera sistemática a lo largo de toda la data. Mencionan que la información se puede codificar parcial o totalmente, lo ideal sería codificar toda la información que se pueda, ya que no se sabe que información puede ser relevante más relevante.

La fase tres es la de buscar los temas, los autores mencionan que se comienza cuando toda la data ya ha sido codificada. Consta de conjugar o integrar códigos para formar potenciales temas y considerar cuáles y cuántos se pueden agrupar en temas "paraguas". Esta fase culmina con temas candidatos y subtemas, en este momento se perciben qué temas son más significativos que otros. La fase cuatro es la revisión de temas que consta de dos niveles. El primer nivel es la revisión de los temas y ver si estos tienen consistencia interna y corresponden a los códigos agrupados, en esta fase se pueden descartar temas y volver a agrupar códigos en caso sea necesario, el segundo nivel es ver si los temas son relevantes a los largo de la información. Finalizando esta fase lo ideal es tener los temas claros (Braun \& Clarke, 2006).

La quinta fase es definir y nombrar los temas, para ello se debe redactar una justificación del porque su elección, analizando los elementos importantes del tema. Los subtemas de los temas sirven para dar consistencia al tema. Al finalizar esta fase se debería poder resumir el contenido y alcance de cada tema en un par de oraciones. La fase 
final es la producción del reporte, al haber obtenido una lista de temas trabajados, desarrollados y analizados, se pasa a producir un reporte. Los autores mencionan que el reporte es como una historia de cómo la información fue recolectada, codificada y analizada, mostrando los temas, su relevancia y los hallazgos que se puedan haber realizado. Es posible que se pueda usar un marco teórico para apoyar los hallazgos del análisis (Braun \& Clarke, 2006). 


\section{Capítulo 3. RESULTADOS}

El objetivo de la siguiente investigación es describir las actitudes que tiene un grupo de docentes escolares peruanos frente a la tecnología de la información como herramienta educativa. Se enmarca dentro de un enfoque cualitativo.

Para el termino actitud se utiliza el modelo metacognitivo. Desde este enfoque las actitudes hacia los objetos son evaluaciones positivas o negativas las cuales se encuentran en la memoria. Existen tres características principales de la actitud según este modelo, la primera es la activación que depende del contexto en el que se encuentre la persona, si bien las actitudes están vinculadas en la memoria con una fuerza determinada, su activación depende de diferentes factores contextuales. La segunda característica es que existen actitudes con valores antagónicos, es decir la actitud que se recupera y utiliza está influenciada por factores como: la experiencia más reciente y del discriminar entre contextos donde la vinculación sea favorable según el contexto. Por último se encuentra la valoración que hace la persona de sus mismas valoraciones es decir la capacidad que tiene la persona para opinar sobre su propia valoración Petty, Biñol y De Marre, 2007 (citado en de los Santos y Cantillo, 2012)

Los participantes de esta investigación son 7 docentes que tienen entre 23 a 46 años de edad 6 mujeres y un varón. Sin embargo, sus actitudes hacia las TIC son las mismas en general, teniendo características particulares que no hacen una diferencia significativa.

Del análisis de los datos se obtuvieron dos actitudes generales cada una de ellas está conformada por categorías que en conjunto conforman la actitud general. Cada categoría ha sido analizada según las tres características de la actitud. En primer lugar se encontró una actitud positiva entre los participantes en utilizar la tecnología durante el dictado de clases, este tema principal está conformado por tres categorías que lo conforman: motivación para los alumnos, captar la atención de los alumnos y uso de las TIC en el proceso. En segundo lugar se halló la actitud de buena disposición hacia las TIC para elaborar las diapositivas, este tema principal también está conformado por tres categorías que lo componen: Material guía para el dictado, integración de información adicional y gestión de tiempo. En las siguientes líneas se mostrarán los resultados 
encontrados según cada tema con sus categorías correspondientes descritas según las características de la actitud.

Tabla 1: temas y categorías

\begin{tabular}{ll}
\hline Temas & Categoría \\
\hline $\begin{array}{l}\text { Actitud positiva en utilizar la tecnología } \\
\text { durante el dictado de clases }\end{array}$ & $\begin{array}{l}1.1 \text { Motivación para los alumnos } \\
1.2 \text { Captar la atención de los alumnos } \\
\text { clase }\end{array}$ \\
\hline $\begin{array}{l}\text { Buena disposición hacia las } \\
\text { elaborar el dictado de clases }\end{array}$ & $\begin{array}{l}2.1 \text { Material guía para el dictado } \\
2.2 \text { Integración de información adicional } \\
\end{array}$ \\
\hline
\end{tabular}

\subsection{Actitud positiva en utilizar la tecnología durante el dictado de las clases}

En primer lugar, se encuentra la actitud positiva en utilizar la tecnología durante el dictado de las clases. Los profesores muestran interés y necesidad en implementar la tecnología en el dictado de las clases, esta actitud general se puede apreciar mediantes sus tres características. Este tema principal está constituido por categorías que lo componen: motivación para los alumnos, captar la atención de los alumnos y uso de las TIC en el proceso. De esta manera estas categorías componen la actitud positiva en usar la tecnología durante el dictado de las clases, las cuales se analizaran según las tres características de la actitud.

\section{Motivación}

Activación según contexto, la cual es la experiencia reciente vinculada en la memoria con una fuerza determinada y su activación depende de diferentes factores contextuales Petty, Biñol y DeMarre, 2007 (citado en de los Santos y Cantillo, 2012).

En relación a la categoría motivación, los docentes evocan recuerdos de su salón en donde los alumnos responden positivamente a los estímulos visuales que se les presentan en clases. Utilizan videos o aparatos tecnológicos para captar más la atención de sus alumnos, durante el inicio de clases o durante su desarrollo. El sujeto 4 utiliza videos para explicarle a sus alumnos temas abstractos, los videos le permite llegar a los alumnos de formar más entretenida con un tema que quizá sin ayuda de un video pueda 
ser difícil de entender. El sujeto 2 inserta en sus clases videos y el uso de los celulares para trabajar con sus alumnos, menciona que se motivan porque les llama la atención y esto hace para él que su clase sea significativa.

Más que todo para motivación y a veces para la explicación de las mismas clases porque como hay videos ya que te explican de forma más lúdica más entretenida a los niños. Por ejemplo si me toca hablar de la energía ya te explica de forma más entretenida que es la energía no, porque a veces son conceptos un poco abstractos para ellos para que entiendan, entonces con el video como que maso menos ellos ya van entendiendo, van afianzando bastante el aprendizaje. (Sujeto 4)

Para proyectar videos de youtube, busco videos de la clase, de un tema y lo proyecto y a veces no los guardo en mi USB como acá hay. (Sujeto 2)

He porque ellos están, he se motivan más. Porque como están todo también el tiempo con la tecnología y usa más la tecnología y están todos en esa onda, se motivan más dicen: “ hay! celular, tecnología “ entonces como que les llama más la atención, ose la clase es más significativa. (Sujeto 2)

Se menciona que utilizar recursos tecnológicos, como videos o canciones son importantes para involucrar al alumno en el dictado de clases. De esta manera, se apoyan en ellas para desarrollar el tema tratado o como agente introductorio. El sujeto 2 menciona que si ve a sus alumnos desanimados el mostrarles un video los anima. El sujeto 5 identifica en el momento que sus alumnos están cansados o aburridos e interviene presentando un video o canción utilizando estor recursos como elementos motivadores. Esto da a entender que el docente toma en cuenta el ánimo, o las ganas del estudiante y a partir de esto realizan acciones para cambiar el estado del alumno, utilizando la tecnología como agente de activación.

A claro de todas maneras mis videos. Que si mi clase no es con video o de repente no hay algo proyectado porque no lo... es como que están asímedios desanimados yo lo noto es sus caritas. "les voy a poner el video" y "yee” todos sí, sí ayuda bastante los videos o los programas en línea que yo uso. (Sujeto 2) 
(...) el inicio para la motivación, en la motivación, en el medio para despertaros. Después de una clase exhaustiva los niños se cansan o se aburren de que uno esté hablando y hablando. Entonces lo que yo hago es ponerles videos, este canciones infantiles (...) Les pongo la canción se levantan y empiezan a bailar, si la saben la cantan pero después de eso les dicto, escriben con más facilidad porque ya despertaron. Entonces al inicio la tecnología, la tecnología al inicio en la motivación para poner el video motivacional del tema ya sea video canción, poema, que sea lo que sea. (Sujeto 5)

El docente 4 hace uso de recursos electrónicos porque le sirve para motivar a los alumnos, se da cuenta que ante estos estímulos los alumnos atienden más y prestan mayor atención, utiliza videos pero también material concreto. El objetivo para este docente es que ellos aprendan motivados divirtiéndose en el proceso. De esta manera el profesor da a entender que existe una facilidad en el aprendizaje la cual puede estar relacionada a la motivación que producen los materiales tecnológicos didácticos.

(...) los chicos atienden más y prestan más atención un video que a una persona que esta con sus papelógrafo explicándoles diciéndoles, más que todo ellos viven haciendo también, así que cuando tengo material concreto también lo aprenden rápido. Pero cuando es video así que ellos miran escuchan creo que ellos aprenden más. (Sujeto 4)

Como te dije me facilita más el aprendizaje. Por ejemplo cuando hemos trabajado los animales invertebrados conseguí un video maso menos cómico y ellos rapidito captaron. Cuando yo les pregunte que es un animal invertebrado solitos hicieron la clase. "son animales que no tiene hueso que no tiene columna" "se dividen en grupos tenemos insectos las arañas" solititos prácticamente se armaron la clase solamente viendo ese video. (Sujeto 4)

El valor antagónico menciona que la actitud que se recupera y utiliza está influenciada por factores como la experiencia reciente y del discriminar entre contextos donde la vinculación sea favorable según el contexto Petty et al. 2007 (citado en de los Santos y Cantillo, 2012).

Los docentes en su mayoría se inclinaron por el aspecto positivo. Mencionan que es favorable utilizar recursos electrónicos para motivar a los alumnos porque desarrolla 
en ellos resultados deseados logrando que se concentren y por ende presten atención a la maestra o maestro durante el dictado de clases, en las siguientes líneas se mostraran estas razones detalladamente.

El sujeto 2 menciona que la tecnología lo ayuda bastante, sobre todo porque logra desarrolla mediante esta las capacidades que ella se propone Sin embargo, trae consecuencias como el que se distraigan viendo redes sociales, mientras utilizan su celular. Es por ello que para el sujeto 2 la supervisión mientras trabajan con tecnología es importante ya que los orienta.

Bastante, bastante. Porque ellos mismos logran desarrollar las capacidades que yo quiero que logren y bueno ayudan pero también no ayuda en algunas partes porque puede ser que por ahí se quisieron pasar a su instragram o a su Facebook. Hay que estar de todas maneras orientándolos y guiándolos. (Sujeto2)

El sujeto 4 hace referencia que la tecnología lo ayuda a llegar a sus alumnos. Acercándolos a situaciones o a cosas que no se pueden ver en ese momento. El llegar a sus alumnos puede estar relacionado a captar su atención o involucrarlos con el tema.

A mi prácticamente me está ayudando un $70 \%$ ya debe estar. Un $70 \%$ para ayudarme a llegar a ellos. (Sujeto 4)

Para hacer más didáctica la clase y cuando sé que no puedo traerles cosas tal vez la tecnología me la remplaza no (...) (Sujeto 4)

Se puede apreciar en el sujeto 5 un rechazo a una enseñanza sin tecnología por que aluden a que sin ella el dictado de las clases se torna aburrido, da a entender que lo importante de la inserción de la tecnología en el dictado es la dinámica que este le otorga. Gracias a la inserción de las TIC se logra la motivación que lleva a que se concentren.

He llevado clases sin tecnología y es algo aburrido porque no osea, los niños aprenden de diversas maneras. No es que uno aprende solo viendo imágenes, entonces si o si tienes que presentarles un video porque eso hace que después se concentren porque ya están motivados (...). (Sujeto 5)

Así también da a entender un rechazo por una enseñanza tradicional, donde los materiales que utilizaban para el dictado, eran imágenes en láminas y uso de palelógrafo para que el maestro desarrolle. El sujeto 5 recuerda lo que le dijo su madre sobre la 
enseñanza hace unos años, donde no existía la tecnología. El proceso de enseñanza no tenía mayor impacto sobre el alumno, por lo que se puede apreciar no había mayor interacción con el tema. En la actualidad sabe que la tecnología es importante para la educación, por ello utiliza videos ya que sabe que estos van dirigidos a sus alumnos. Esto da a entender que este profesor elige sus materiales de clases en base a las características de sus alumnos.

No es solamente su profesora mostrándoles imágenes o mostrándoles un papelote, he dado clases así, he visto la diferencia. (Sujeto 5)

Porque les mandaban a leer libros mas no ver video, mi mamá me dice ahora debe de ser diferente. Porque antiguamente no se aprendía muy bien, osea si se aprendía pero era más memorístico. En cambio ahora no ahora llega a ellos mismos, los video que les presento no es que son para grandes, va directo para los niños son casos dibujitos dibujitos que van de frente al tema. Definitivamente la tecnología es importante para la educación. (Sujeto 5)

La valoración se refiere a la capacidad que tiene la persona para opinar sobre su propia valoración Petty et al., 2007 (citado ende los Santos y Cantillo, 2012).

En relación a esta característica se encuentra valoraciones diferentes entre los docentes, sin embargo el tema que se observa y tienen mayor presencia es el impacto de las TIC en los alumnos como: el interés que tienen los alumnos en utilizar aparatos tecnológicos para hacer trabajos, el impacto de la información que se presenta a partir de videos que acerca al alumno a una realidad de la que no puede ser parte, el utilizar tecnología debido a la importancia que tiene esta en la vida diaria de los estudiantes.

En relación a la ayuda que brinda la tecnología para la motivación, el sujeto 2 opina que utilizar sus celulares fomenta en los alumnos el interés hacia el aprendizaje y hace que esta experiencia de aprendizaje les sea significativa, viéndose posteriormente reflejada al momento de la evaluación.

¿Qué opinas acerca de que la tecnología te ayuda a la motivación?

El que cuando, es que no es algo tan común que el profesor te diga de repente "ya vayan a sacar sus celulares para abrir tan programa, o van a usar su cronometro o van a usar su cámara para tomar una foto" entonces como que ahí ellos se motivan y le toma más interés al tema o a la clase y eso es más significativo para ellos. (Sujeto 2) 
El interés de ellos, su impacto en la clase, hee y luego también los resultado, este... cuando yo voy a dar mi examen o una práctica y les ha llegado el tema porque lo hacen porque lo resuelven. (Sujeto 2)

Para el sujeto 4 ante la facilidad de aprendizaje por medio de la tecnología opina, que es una herramienta útil, relacionado al impacto que tienen los videos con nueva información. El utilizar una ventana de internet para mostrar este tipo de eventos a los niños, los acerca a una realidad de la que no puede ser parte. Por medio de del internet se pueden ver videos y fotos que facilita el aprendizaje al alumno porque le muestra dinámicamente contenidos que lo acercan a la realidad.

¿Qué opinas acerca de que la tecnología te facilita el aprendizaje?

una herramienta muy útil, porque los acerca bastante a ellos. Hay cosas que uno ve en otros lugares y lamentablemente no puede ir porque el eclipse no iba a ser acá en Perú, no podíamos verlo en cambio la tecnología nos abrió ese ventana para poder vivirlo y verlo y cuantas cosas así podemos así podemos informarnos no? Por ejemplo una vez vimos un video de que cosas había en otros mundos, por ejemplo (...) (Sujeto 4)

El sujeto 5 ante la cercanía que branda la tecnología para abrir un mundo de posibilidades opina, que la tecnología tiene una importancia muy alta debido a que los chicos hoy en día tienen a la tecnología como parte de su día a día y presentar en clases materiales sin la ayuda te la tecnología seria aburrido para ellos. De esta manera es posible que la profesora utilice la tecnología debido a la magnitud que tiene en la vida diaria de los estudiantes.

¿Qué opinas acerca de que la tecnología te abre un mundo de posibilidades? Como mencionaste hace un momento

Es sumamente importante, ahora en la educación es sumamente importante la tecnología porque sin tecnología no sería lo mismo. Porque hora los niños están metidos con toda la tecnología encima, y que hagan una clase video sin videos, sin nada es sumamente aburrido. (Sujeto 5)

\section{Captar la atención}

Dentro de la característica activación según contexto, se puede apreciar que las experiencias que vienen a su memoria están relacionadas al momento de desarrollo de la 
clase. Para el sujeto 1 el uso de la tecnología se da sobre todo en el desarrollo, para poder explicar el tema y en ocasiones lo utiliza para la introducción. El motivo es emplear materiales visuales, videos, imágenes, es que hoy en día los niños se desarrollan en un contexto ligado al uso de celulares, tablets y laptos.

Sobre todo en el proceso, para la explicación del tema, para producción de ellos, y bueno para algún tipo de producto de la clase. También puede ser para introducción al tema. Porque a veces antes de empezar el tema les pongo un video o imágenes proyectadas o un juego que es esté relacionado con el tema. (Sujeto 1)

Actualmente creo que es necesaria porque los chicos están muy ligados a la tecnología, osea a excepción de antes no estaban tan cercados. Pero ahora ellos tienen celulares, tablets, laptops. Tú le hablas de diapositivas y saben de eso. Son más visuales, necesitan ver videos, o que tú le proyectes cosas así, siento que es muy importante. (Sujeto 1)

En el sujeto 7 se ve un claro ejemplo de cómo utiliza el internet para poder conseguir un compás virtual para enseñarles cómo se utiliza, logrando que los estudiantes empleen su propio compás, teniendo contacto con el objeto de manera concreta, luego de haber sido enseñado mediante un canal visual. El docente menciona que intento hacer la actividad empleando un compás grande, pero no tuvo el resultado que esperaba.

Por ejemplo si quiero usar el compás con ellos, usualmente que hago es utilizar un programa, porque compás grande a veces no funciona mucho. Entonces yo lo pongo junto con el proyector y les enseño como se trabaja, les enseño las partes todo y entonces empiezan a trabajar. Entonces como ellos tienen el compás de forma concreta ver cómo se mueve como se trabaja no. Es así como lo utilizo yo, cuando algo no se puede representar tan grande no. También como para trabajar materiales didácticos, alguna elaboración (...) (Sujeto 7)

Para el sujeto 6 un componente importante que influye en que el docente use las TIC es la respuesta que tiene del estudiante al presentarle el material tecnológico, "necesito cosas que los despierten" el alumno se involucra con el tema y el docente capta mayor atención e interés a través de videos, diapositivas dinámicas con imágenes. 
Casi siempre uso lo que es videos, uso a la hora de dar mi clase presi, casi siempre uso tecnología para ellos, para no aburrirlos. Porque si uso solamente libros o fichas se aburren, como yo enseño historia los voy a tener aburridos, van a dormirse entonces no, necesito cosas que los despierten. (Sujeto 6)

Respecto al valor antagónico, en los docentes predomina la actitud positiva en utilizar la tecnología para captar la atención durante el dictado de las clases.

Se obtuvo que el sujeto 1 utiliza estrategias que le permite llamar la atención de sus alumnos, utilizando colores, textos sintetizados e imágenes. Esto quiere decir que no utilizan la tecnología solo por emplearla con sus alumnos, si no que trabaja el material de tal manera sea atractivo para los estudiantes. Prefiere tener el material de apoyo ya realizado a estar escribiendo en la pizarra le demora mucho tiempo y pierde contacto con sus estudiantes.

Siento que es más rápido, que capta la atención de la mayoría. Porque a veces el estar escribiendo, te demora, estas volteado y no puedes ver a los chicos. Bueno para mi es más fácil porque yo me demoro mucho es escribir y siento que las ideas están más sintetizadas, puedes ponerle imágenes, los colores les llama la atención, puedes agregar allí videos. A mí me parece. (Sujeto 1)

Otro punto importante que menciona el sujeto 7 es que la tecnología te permite compartir la información con todo el salón, es decir que a partir de una proyección todos los alumnos reciben la misma información. La información se visualiza en un mismo tiempo a todos los estudiantes, por lo tanto todos reciben la misma información al mismo tiempo. El poder recibir la información de manera colectiva hace que el aprendizaje sea en conjunto.

Ayudan bastante en sí, en lo que es la implementación del aprendizaje, no también hay que saber usarlo en si. Si no lo sabes usar va a ser un mal para ti también no (...) les enseñas a todos entonces haces de que más personas puedan ver a partir de una pantalla chiquita a una pantalla grande. Todos ven juntos en conjunto y aprenden. Haces que el aprendizaje sea de manera conjunta. (Sujeto7)

Para el sujeto 6 el utilizan métodos tradicionales al parecer no causa un impacto significativo en la enseñanza, ya que el estudiantes no atienden si el estímulo que se le muestra no es de su interés por que se aburren. Es por ello que este profesor tiene en 
cuenta que para que sus estudiantes aprendan tiene que presentarle la información de manera que ellos se diviertan aprendiendo.

Porque de esa manera los capturo a ellos no, usar métodos convencionales a veces hace de que ellos no, no, no quieran escucharte no quieran tomarte atención porque ellos se aburren. Uno como docente tiene que buscar la manera de hacer que ellos aprendan, entiendan y lo hagan de una manera que se diviertan no, el aprendizaje es eso básicamente. (Sujeto 6)

Por ultimo respecto a la característica de la valoración de su valoración encontramos evaluaciones diferentes entre los docentes respecto a los siguientes temas: Material visual tiene el poder de entretener al alumno, acercamiento a lugares nuevos o herramientas novedosas.

Relacionado al material visual el cual tiene el poder de entretener al alumno, el sujeto 1 menciona que los niños ya están acostumbrados a estímulos visuales, por lo que el material con dinamismo son los que le van a llamar más la atención, recalcando que el material a presentar tiene que contener la información importante que se quiere enseñar. ¿Qué opinas acerca de que con ellas puedes captar la atención de tus alumnos? El captar la atención de los alumnos parte porque ellos están acostumbrados a estímulos visuales que sean interesantes y tengan la información importante. Así que las diapositivas te brindan estas características, que mantienen conectado al alumno con la teoría que quieres enseñar por ser un estímulo conocido y aceptado por ellos. (Sujeto 1)

Respecto a la posibilidad que te da el internet para acercar a los alumnos a lugares nuevos o utilizar herramientas novedosas, el sujeto 6 y 7 mencionan que estos son de gran ayuda, porque le da la oportunidad al alumno de conocer un entorno que no había visto antes, generando dinamismo en las clases, sobre todo por los programas que se tienen hoy en día como el google maps. Mencionan que es posible que estas actividades repercutan más en alumnos que no conoce el lugar enseñado que en aquellos que ya han tenido algún contacto con el medio. El utilizar herramientas nuevas para ellos con las que no han tenido contacto, les genera un enganche con el tema, por ende ganas de aprender.

¿Qué opinas a que la tecnología te ayuda a trasladarte a otros lugares para el aprendizaje? 
Ha que es excelente porque no todos cuentan con los recursos. (...). Incluso en el tema de google maps, también osea una vez estábamos hablando de las calles las cosas y los mande a que investiguen ya cada uno iba a investigar una calle o paralela de lugares ajenos lima no! No vale lima no vale perú, Y empezaron a buscar que en Barcelona en Estado Unidos y ellos agarraban el google maps y empezaban a caminar por ahi y veían "oie mira y ay personas" y hay eso y hay el otro y les servía bástate es dinámico hee y es bastante llamativo para el que no tiene la oportunidad es llamativo y para quienes la tienen de repente no, no, no sea tan llamativo para ellos. Porque de repente es algo que viven osea una vez a dos veces al año pero para quien no si en verdad. (Sujeto 6)

¿Qué opinas acerca de que la tecnología ayuda bastante en sí, en lo que es la implementación del aprendizaje?

Que te permite mostrar cosas nuevas, por ejemplo en el caso del compás ellos no sabían que existía un compás virtual y eso los engancha con el tema y les da ganas de aprender cómo funciona. Entonces el utilizar la tecnología llama la atención porque engancha al estudiante con un recurso que ellos manejan muy bien. Es mezclar la manera con cómo se he trabajado siempre con la manera en la cual los niños se desenvuelven en su día a día, lo que para ellos es cotidiano. (Sujeto 7)

\subsection{Uso de las tic en el desarrollo de la clase}

Relacionado a la característica de activación según contexto el docente evoca a su memoria el utilizar la tecnología en el proceso de la enseñanza.

El sujeto 3 hace uso de la tecnología para mostrar contenido relevante de su clase en el desarrollo. Así mismo, se menciona que el utilizar ya una diapositiva realizada toma menos tiempo que estar escribiendo en la pizarra y se evita darles la espalda a los estudiantes. De esta manera el profesor presta más atención a sus alumnos.

Normalmente uso todo lo que es tecnología en el proceso, ya para mostrar una gramática, un video un ejemplo. Me parece un recurso bien fácil. Porque estar escribiendo toma bastante tiempo y estar escribiendo toma bastante tiempo. 
Los salones son numerosos y los chicos se alborotan y darles la espalda es darle la oportunidad para que hagan algo fuera de tu clase, o que conversen, o que se golpeen, muy rápido. Entonces como tienen que estar en contante observación usos los instrumentos para que sea más rápido. (Sujeto 3)

En el caso de la enseñanza de un idioma, la tecnología le permite al sujeto 3 mostrarles a sus alumnos audios del idioma que enseña, con la finalidad de que sus alumnos escuchen la pronunciación de una persona nativa buscando que tengan contacto con el idioma natural.

(...) pronunciación... diferente tipo de hablar si vas a estados unidos, Inglaterra. Entonces me sirve bastante por el audio, si escuchar a otra persona sea de Inglaterra, sea de otros paisas hay bastantes acentos al final es la misma lengua. Les abre la mente y al final les sirve para que no se encajen en lo que yo les digo. (Sujeto 3)

Respecto al valor antagónico, se evidencian aspectos positivos que le sirven al docente en el desarrollo de la clase. El sujeto 3 encuentra en el internet todo tipo de recursos que lo pueden ayudar en sus clases, y pueden ser usadas para ser desarrolladas como ejercicios o actividades. El docente considera que tener la teoría y combinarlo con el manejo de la tecnología le permite mejorar como profesional.

Me gusta mucho por los recursos que tiene. Si necesito un ejercicio o un ejemplo de cómo podría explicar algunas cosas fuera de lo que yo ya se, puedo conseguir más información de otras herramientas. Puedo también ayudarme en el tema buscar ejercicios, actividades trascendentes en la clase. Puedo mejorar mi metodología osea puedo mejorar dentro de ser un profesional con más teoría, actividades. Hay uff toda una caja de recursos. (Sujeto 3)

Los videos más que todo creo que lo más importante dentro de proyecta algo son las películas y el audio que es lo más difícil de presentar con solamente hojas, no hay otra opción. (Sujeto 3)

Dentro de la última característica de esta actitud se encuentra la valoración de su valoración. 
El sujeto 3 ante usar tecnología que le permite ingresar a mayor información opina, le permite criticarse a sí mismo porque no basta con tener toda la información necesaria ya sea de internet o de libros, lo importante es saber crear materiales utilizando estrategias. Y es allí donde busca en internet diferentes formas de presentar el tema para que este sea agradable y novedoso para sus alumnos utilizando diferentes estrategias de enseñanza.

¿Qué te parece que el usar tecnología te permite ingresar a mayor información? Creo que te permite criticarte a ti mismo, osea si bien uno tiene toda información busca libros de acuerdo a la universidad, profesores y todo eso, cuando uno va hacer una clase de repente pide un poquito más de información para saber que más puedes decir o de repente prepararte para los problemas que pueden surgir no. Vas a decir una clase, piensas que los chicos van a reaccionar y también tienes que pensar en los problemas, que es lo que no van a captar que es lo que van a preguntar. Entonces buscas en internet, acerca de diferentes formas de decir el tema y como que si vas con la mente abierta dices por aquí puede haber entrado o mejor por aquí podría poner este como ejemplo. No solamente hay una forma de enseñar hay varias y tienes que abrirte. (Sujeto 3)

\subsection{Buena disposición hacia las TIC para elaborar el dictado de clases}

En segundo lugar, se encuentra la buena disposición hacia las TIC para elaborar el dictado de clases. Los profesores muestran apertura en el uso de internet para emplear sus materiales de clases y presentarlos para el desarrollo sus sesiones. Este tema principal está constituido por categorías que lo componen: Material guía para el dictado, integración de información adicional y gestión de tiempo. De esta manera las categorías que componen la actitud se analizarán según sus tres características.

\section{Material guía para el dictado}

En líneas generales, se trata de las diapositivas que elaboran los docentes para sus alumnos, cumpliendo de función guía para su secuencia de clase, por lo que se apoyan de ella en el dictado. 
En relación a la activación según el contexto, el sujeto 2 utiliza el power point para elaborar sus dispositivas y se asegura de tenerlo guardado en el USB. Menciona que no usa pressing porque no lo sabe utilizar y porque este tiene una nube en la que se guardan los trabajos y al no tener internet permanentemente en el colegio tiene temor de elaborar sus diapositivas y no poder usar su material al momento de clases.

heee... uso el Power point, no uso el pressing, lo intente usar... no me han enseñado mucho esa aplicación. Pero creo que es usando internet, entonces a veces me da un poco de miedo que de repente se valla el internet, entonces prefiero hacerlo en el ppt para que quede en mi USB. (Sujeto 2)

El sujeto 7 utiliza todos los recursos que puede para elaborar sus diapositivas, en caso no encuentre el material que necesita en internet utiliza libros y mediante la tecnología trastalada las imágenes a sus diapositivas, dejando su material listo como lo necesita.

Utilizo lo que son los libros, que a veces no encuentro en internet pero si o encuentro en un libro. Entonces lo que hago es con la impresora lo escaneo y lo que hago ya partir del programa lo recorto y lo coloco en la diapositiva y ya está formadito. Porque hay cosas que no hay en internet a veces lo que uno busca a veces no está, entonces como tengo libros digo " $y$ ahora como hago no, no mejor lo escaneo" lo escaneo lo recorto allí en la misma computadora y lo pego en la diapositiva y ya está. (Sujeto 7)

Respecto al valor antagónico se puede observar una actitud favorable hacia las diapositivas.

El sujeto 2 menciona que las dispositivas la ayudan a tener una secuencia de clase. Así mismo el sujeto 7 menciona que las diapositivas la organizan y le permiten tener todo listo para enseñar. Cuenta que han habido oportunidades donde no ha podido hacer sus materiales de clase y al llegar al colegio busca como hacerlo y encuentra estrategias que estar relacionadas al ámbito virtual y tiene que pensar en hacer otra cosa ya que en ese momento no puede hacerlo virtual. Menciona que estas herramientas además son motivadoras para sus alumnos.

Sí, sí es necesario, porque con eso te ayudas también para la secuencia de tu clase. (...)(Sujeto 2) 
me permite organizar la clase y tener todo listo para enseña, las diapositivas me dan la herramienta de tener atentos y motivados a los chicos para que presten atención. Por ejemplo me sucedió una vez o dos, tres veces me ha sucedido que no me había preparado para poder enseñar, y dije ya veré que hago llegando. Entonces veo y me doy la sorpresa que es este tema y entro al instante al correo "ya podría usar esto, pero es virtual, no!” ya y me ponía a pensar otra cosa. Entonces realmente es necesario porque así, es que con lo virtual haces que al estudiante le llame la atención bastante y aparte este entienden más no se porque entienden más con lo virtual. (Sujeto 7)

En relación a la valoración de su valoración en este caso se encontró una que se comparte y esta relaciona a la organización que les da a los docentes tener su diapositiva como guía de clase.

El sujeto 2 ante la ayuda que le brinda el ppt para tener una secuencia de clase opina que le permite ordenar sus ideas para poder transmitir lo que él desea. El sujeto 7 ante la organización que le brindan sus diapositivas para enseñar, menciona que el tener una secuencia oportuna con materiales adecuados le permite al alumno motivarlo y a raíz de esto que aprenda. Ambos resaltan la importancia de elaborar sus diapositivas como una guía para ellos mientras enseñan.

¿Qué opinas acerca de que el ppt te ayuda a tener una secuencia del tema que vas a enseñar en tu clase?

Opino que está bien que me ayuda a poner ordenarme y que ellos también se ordenen, no?

(...) porque es beneficioso, me ayuda bastante a ordenar mis ideas para poder transmitir lo que quiero. (Sujeto 2)

Qué opinas sobre, lo que me comentaste hace un momento acerca de que las diapositivas te permiten organizar la clase y tener todo listo para enseñar? P: opino que la organización es un punto muy importante para que el profesor pueda guiar su clase, si no me va a pasar lo que sucedió cuando lo hice mis materiales que no estaba organizada y no pude utilizar materiales que en ese momento podían ser muy útiles. No solo la tecnología permite que el chico aprenda, también el tener una secuencia oportuna con materiales adecuados. 
Entonces es un complemento el tener organizada mi clase utilizando herramientas cercanas a los chicos para motivarlos. (Sujeto7)

\section{Integración de información adicional}

Respecto a la activación según contexto, el sujeto 1 menciona que el elaborar las diapositivas le da la posibilidad de repasar el tema "al elaborarlos repaso el tema que voy a ver con los niños". Debido a que al momento de elaborarlo ya ha tenido contacto con el contenido que va a dictar y esto la hace sentir más preparada.

El elaborar sus diapositivas la hace sentir más preparada. La docente inserta en sus diapositivas imágenes o información adicional de libros, porque cree que será útiles para sus estudiantes y al mismo tiempo la ayuda manejar la información al momento del dictado.

Porque al elaborarlos repaso el tema que voy a ver con los niños, y creo que estoy más preparada, porque ya vi el tema antes de dictarlo. Además muchas veces incluyo información adicional que encuentro y que no están en sus libros. Que considero que es importante que ellos la manejen. (Sujeto 1)

Utilizo información de páginas en internet también información de los libros. Pero si hay información adicional que la puedo encontrar yo fuera del libro. Entonces la información adicional yo se las doy en las diapositivas. (Sujeto 1)

En relación al sujeto 3 este realiza sus materiales tomando en cuenta imágenes de internet o creando o agregando ejercicios de libro. Menciona que es importante utilizar los ejemplos o información del libro porque después lo chicos se dan cuenta que la información no la tienen en su material.

claro! de vez en cuando jalo información, imágenes de internet y otras veces también las hago yo. Osea fusiono los dos, veo las imágenes que estoy descargando si tienen similitudes con lo que estoy enseñando solo lo pongo allí y luego al otro lado también veo ejercicios del libro y lo pongo allí y luego otro ejercicio. (Sujeto 3)

los dos porque si solamente uso la del internet cuando vena el libro van a decir "oye que es esto, porque me están enseñando lo otro si nunca lo voy a utilizar" (Sujeto 3) 
El sujeto 4 se enfoca es agregar información adicional para cubrir las dudas de sus alumnos e ir preparada para cuando presente el tema ante su clase. Utiliza los medios que tiene a la mano para poder brindarles una información completa ya que menciona que en ocasiones la información que dan los libros es general. Aparente mente es una docente que se procura por darles mayor información a sus alumnos y ellos con lleva a mayor información a procesar.

(...) trato de prácticamente de usar ambos porque a veces el libro te lo dice muy general o no te explica el por qué y como yo sé que ha este salón le gusta saber el porqué de las cosas, ya recurro un poco a internet. Entonces uso los dos medios para poder armar bien mi clase y estar preparada para ellos, más que todo. (Sujeto 4)

El sujeto 5 tiene una manera particular de hacer sus materiales. Sigue una serie de pasos que le permiten presentar la información ya organizada. Primero investiga acerca del tema, realiza resúmenes en forma de organizadores. Menciona que al presentarle la información sintetizada a los alumnos se les hace más fácil copiar la información.

Proceso del profesor en elaborar sus ppts: primero investigo acerca del tema, una vez que ya he investigado saco resúmenes hechos por mí. Hago resúmenes, pero no los escribo si no hago mapas conceptuales cosa que ellos ven, se les hace más fácil comprender con palabras pequeñas el tema. A diferencia que les muestro un texto enorme "miss todo eso vamos a copia" no! En cambio si se les muestra el organizador en si se le hace más fácil copiar la palabra y las imágenes. Entonces yo presento el organigrama, la organización, mapa conceptual, mapa de llaves, cualquier organizador y luego su imagen, ese es mi ppt. (Sujeto 5)

En cuanto al valor antagónico a elaborar dispositivas integrando información adicional se muestra positivo.

El sujeto 1 menciona que si se sabe utilizar adecuadamente las herramientas tecnológicas y se tiene un objetivo claro no le ve ningún aspecto negativo.

no yo particularmente no tengo ninguna crítica ni aspecto negativo, hay que saber usarlo y tener el objetivo claro. (Sujeto 1)

Para el sujeto 3 apoyarse de la tecnología introduciéndola en su curso le parece más provechoso, sobre todo las películas que están dentro de un contexto. Menciona que 
la creación de sus materiales lo hace según su criterio tomando en cuenta que va dirigido a un tipo de alumnos y revisándola para que este presentable y adecuada "información que le vas a dar a ellos tiene que pasar por tu filtro".

Le agrada mucho los recursos que brinda la tecnología porque le permite integrar más actividades y conseguir ejemplos de cómo explicar algunos temas. Hace referencia q que le permite ser un mejor profesional porque no solo manejaría la teoría sino tendía actividades para realizar.

Me ayuda bastante porque sin bien para usar cosas realistas, (...) creo yo que si solamente cogemos el proyector para ver imágenes, nada más tampoco le veo tanto sentido, puesto que tú puedes agarrar un papelote un día anterior y ponerlo y es básicamente lo mismo. Creo que en lo que podría ayudarnos más, más, más la tecnología dentro de mi campo es películas en movimiento, por ejemplo si te voy a enseñar que es un árbol es mucho mejor ver un árbol donde debe de estar, en el campo moviéndose con la briza. (Sujeto 3)

si! Claro, como tú explicas algo que no elaboras. Osea tú tienes que crearlo según tu criterio osea tú tienes q ver la información, que información que le vas a dar a ellos tiene que pasar por tu filtro. (Sujeto 3)

me gusta mucho por los recursos que tiene. Si necesito un ejercicio o un ejemplo de cómo podría explicar algunas cosas fuera de lo que yo ya se, puedo conseguir más información de otras herramientas. Puedo también ayudarme en el tema buscar ejercicios, actividades trascendentes en la clase. Puedo mejorar mi metodología osea puedo mejorar dentro de ser un profesional con más teoría, actividades. Hay uff toda una caja de recursos. (Sujeto 3)

El sujeto 5 menciona que el no tener internet no es nada agradable, sí podía realizar sus diapositivas con la ayuda de la tecnología pero sin el internet no tenía acceso a imágenes para complementar visualmente su material. Por ello tenía que imprimirlas o dibujarlas. Lo que permite el internet es acceder a gran cantidad de información en el mismo momento. En la internet por lo general los temas están actualizados, justamente esto es un aspecto que esta profesora resalta ya que debido a la verificación que hiso en internet se dio cuenta que el dato que extrajo del libro antiguo estaba equivocada.

Variedad de materiales. ah! He trabajo sin internet y no es nada bonito, porque no tienes imágenes de donde sacar. Por ejemplo el año pasado estaba sin internet 
yo, lo que hacía era presentarles el ppt de la información y aparte imprimía imágenes o dibujaba porque no tenía internet. Pero ahora este año si! si puedo imprimir, puedo mostrarles la imagen en el ppt porque hay internet. En el internet hay un montón de imágenes que puedes usar. Tú pones un tema y te sale diferentes imágenes para que puedas usarlas, cortar, modificarlas, pegarlas encima. Osea depende de la creatividad que tenga uno. (Sujeto 5)

como te digo todo no es cierto, entonces tengo un libro. Imagínate que no tenga un libro y busque un tema, por ejemplo una vez me paso con los 5 continentes, 6 continentes, no! De los océanos use un libro antiguo y no estaba actualizado y como no tenía internet use esa información, cuando vi, viene acá temprano para corroborar porque no tenía internet, viene acá a corroborar y no eran esos océanos. (Sujeto 5)

Relacionado a la característica de valoración hay diferentes opinones entre los docentes como: crear material nuevo y tener mejor manejo sobre él, facilidad al momento de crear o modificar diapositivas y satisfacción al acceder a mejor información mediante el internet.

El sujeto 1, menciona que el poder elaborar el material le permite tener mejor manejo sobre el tema porque hay información nueva o actual que llega a conocer antes de dictar las clases. Hace referencia a la preparación como la información que debe de manejar durante la explicación, menciona que este se da conforme se van realizando las diapositivas.

¿Qué opinas de que el elaborar material te prepara para el dictado de las clases? que me da la oportunidad de manejar mejor el tema y ver si hay información nueva acerca del tema o si hay algo en la actualidad algo que esté relacionado con eso. Me da la oportunidad de crear todo el material y de conocerlo y no llegar y estar perdida. Creo que la preparación es importante y esta se da con forme vas haciendo el material. (Sujeto 1)

El sujeto 3 sobre menciona que la tecnología lo ayuda bastante para usar videos, ante esto opina que le parece importante poner videos porque les permite escuchar. Pone bastante énfasis porque al parecer es el recurso electrónico que le apoya más en relación 
al idioma que enseña realistas, el audio permite que sus alumnos discriminan la manera en la que se pronuncia el idioma, les permite ver diferentes realidades.

¿Qué opinas sobre lo que mencionaste acerca de que la tecnología te ayuda bastante porque sirve para usar cosas realistas?

Me parece bastante importante porque poner videos los ayuda a escuchar el idioma de origen. Porque, en los videos salen diferentes tipos de pronunciación... diferente tipo de hablar si vas a estados unidos, Inglaterra. Entonces me sirve bastante por el audio, si escuchar a otra persona sea de Inglaterra, sea de otros paisas hay bastantes acentos al final es la misma lengua. Les abre la mente y al final les sirve para que no se encajen en lo que yo les digo. (sujeto 3)

En relación a la valoración de su valoración, el sujeto 5 ante la variedad de información en relación a imágenes y material para elaborar sus clases, opina que siente satisfacción ya me por medio del internet puede acceder a mejor información esto le permite ver diferentes áreas y obtener información.

¿Qué opinas acerca de lo que me dijiste, que el internet te da variedad de información de imágenes y de material para elaborar tus clases?

Estoy тиy feliz, porque no solo es en páginas de internet si no también, el ministerio de educación está ligado a esto. Puedes entrar a MINEDU y te salen un montón de sugerencias e páginas en las que puedes sacar de diferentes áreas, entonces yo estoy muy feliz con el internet definitivamente. (Sujeto 5) 


\section{Gestión de tiempo}

La Buena disposición hacia las TIC para elaborar el dictado de clases está, relacionado al ahorro de tiempo que tienen los docentes al hacer sus materiales con la ayuda de la tecnología.

En relación a la activación según contexto, el sujeto 6 realiza sus diapositivas recopilando toda la información que necesita, ya sea de libros o del internet. Trata de mostrar un material que pueda ser entendido por sus alumnos y esté resumido porque es de esas diapositivas que los alumnos toman nota.

ya he con mis diapositivas o con el presi, yo lo que trato de hacer es rimero recopilar la información. Po lo general no siempre busco la de internet porque no siempre tiene la información exacta. Trato de trabajar con los libros que ellos trabajan o con los libros que yo trabajaba cuando estaba en la universidad y de allí voy sacando la información más importante. Por lo general trato de yo resumírselas porque al final lo que yo copio en la diapositiva es lo que ellos van a tomar nota. Entonces vamos pasando diapositiva y yo voy hablándoles más, ellos también van tomando nota si es que quieren, si ese que se le da la gana también, (Sujeto 6)

El sujeto 4 a diferencia del sujeto 6 ve la economía del tiempo al momento de dictar su curso. Muestra dedicación al hacer su material se, enfoca en utilizar poco texto he imágenes, menciona que ella mientras explica va aclarando los temas.

(...) lo que hago es si voy hacer un tema colocar más que todo, imágenes y poco texto, porque ellos no son mucho de leer así en diapositivas no? Entonces lo que hago es más que toda es poner imágenes y con las imágenes vamos creando la información y yo les voy aclarando. (Sujeto 4)

En relación al valor antagónico tiene una actitud favorable al internet, el sujeto 6 menciona una experiencia pasada donde no tenía proyector y ella tenía que ver desde su laptop la diapositiva que había realizado y copiarla en la pizarra. Con esta experiencia de por medio menciona que el utilizar la tecnología le permite avanzar con mayor rapidez. Sobre todo cuando el trabajo es extenso, el tener una laptop y avanzar las dispositivas le permiten tener tiempo libre para dedicarse a ella. En relación al ámbito negativo es que al usar la laptops uno tiene diversos distractores, en su caso el Facebook está vinculado a su laptop por lo que le aparecen las notificaciones y estos anuncios hace que se distraiga 
(...) muchos, he realizado palelógrafo a mano o he trabajado con una pizarra $100 \%$ porque en colegio nacional no había proyector, yo llevaba mi laptop para aminorarme el trabajo y poder trabajar ahí, y una vez que veía de la laptop proyectaba, osea veía de mi laptop y hacia el esquema. Pero si pues la tecnología me aminora mucho el trabajo. Me hace poder avanzar y avanzar más rápido y yo poder trabajar más rápido porque lamentablemente un profesor nunca termina de trabajar estoy acá de 8 de la mañana a 4 de la tarde y llego a mi casa a las 5 y a las 5 me doy cuenta que tengo cosas que revisar o cosas que hacer entonces, nunca osea nunca tiene tiempo para ti, nunca puedes irte a la peluquería o hacerte las uñas osea no puedes, no puedes, porque no hay tiempo. Entonces el tema de que puedo usar la computadora para ir avanzando ya me da chance de tener al menos o sábado o domingo libre. Sujeto 6)

Pero si si, el tema en contra es que a veces te distrae, no están las aplicaciones, igual prendes la laptop, bueno mi laptop tiene eso no, que lo prendes y igual fb siempre está abierto no, así abra la página o no me salen las notificaciones, se levantan, se levantan. Y sale algo que me interesa y lo abro y ya! Me perdí una hora y cuando me doy cuenta se pasó una hora "como se pasó una hora si solo estaba viendo eso”. Entonces por ahí esta el lado negativo. El lado positivo es que ganas tiempo pues no. (Sujeto 6)

En relación a su valoración de que la tecnología le permite trabajar más rápido el sujeto 6 opina que le encanta porque encuentra materiales de manera más rápida que puede agregar a sus dispositivas ni perder el tiempo de buscar en un libro y copiarlos a sus ppts. Está a favor de la tecnología porque le permite elaborar su material eficazmente.

Qué opinas acerca de lo que me haz mencionado que la tecnología te ha permitido trabajar más rápido?

P: no, a mí me encanta eso! Porque encuentro materiales de manera más rápida, no tengo que buscar en libros. Así busque en libros tendría que pasarlo a la computadora. El internet me permite copiar y pegar ya luego lo modifico. Estoy a favor de la tecnología 100\%, si se trata de mí, no, de elaborar algo para los chicos si! Elaborar las fichas, las rubricas, estoy $100 \%$ a favor. (Sujeto 6) 


\section{Capítulo 4. DISCUSION}

Para los docentes los videos tienen la característica de motivar a los alumnos, influyen en la adquisición del conocimiento, es decir hacen las clases más dinámicas para el alumnado permitiendo enseñar didácticamente facilitando el aprendizaje. Según (Bautista, Martinez, \& Hiracheta, 2014) las herramientas tecnológicas despiertan interés en los estudiantes y al mismo tiempo hacen que los estudiantes se encuentren motivados por su propio aprendizaje con las actividades que el docente lleva a clases. El objetivo es que los estudiantes aprenden con mayor entusiasmo cuando se involucran y les es más significativo ya que se encuentran trabajando con herramientas que conocen y utilizan diariamente, el docente debe ser original en el entendido de anular lo tradicional, ser creativo, auténtico e innovador.

(Bautista, Martinez, \& Hiracheta, 2014) mencionan que la Motivación es el incentivo que lleva a la persona a poder cumplir lo que tanto desea, de ello se desprende la capacidad de comprensión que se tiene para alcanzar los deseos humanos. Por ello se puede decir que los materiales didácticos contribuyen a generar en los estudiantes expectativas sobre lo que van aprender, que los promueve a trabajar por el logro de los objetivos.

Es importante mencionar que el uso de la tecnología en la educación para los participantes tiene como finalidad lograr que el alumno no solo se sienta motivado, sino que comprenda mejor los conceptos o la información que se le presenta. Morrissey (2008) menciona que el utilizar contenidos digitales de buena calidad enriquece el aprendizaje y puede, a través de simulaciones y animaciones, ilustrar conceptos y principios que de otro modo serían muy difíciles de comprender para los estudiantes.

Como menciona (Valverde, 2011), los estudiantes necesitan nuevas herramientas para el aprendizaje, ser activos en la búsqueda informática, desarrollar competencias para comprender por sí mismos, hasta dar significado a la información que obtienen.

Es posible que, si los profesores observan a sus alumnos motivados, prestando atención cuando usan material didáctico como imágenes, información acompañada de videos, etc. repliquen sus prácticas educativas en una siguiente clase con la misma sección u otra del curso. La tecnología brinda una gran cantidad de herramientas, espacios o recursos que sirven como material didáctico. 
(Tejedor \& García-Valcárcel, 2006) afirman en su investigación que los docentes, de ambos géneros, muestran una actitud notoriamente positiva frente a las nuevas tecnologías y su utilización en su trabajo educativo. Según su estudio, éstos reconocen que usar la computadora para enseñar, no solo les gusta, sino que incrementa la participación activa de sus alumnos.

Según (Torres, 2010), para mejorar la calidad de la enseñanza y el aprendizaje, las tecnologías educativas deben adaptarse a las nuevas tecnologías. Esto facilitaría el acceso de los estudiantes a la educación, en el marco del desarrollo tecnológico.

En la investigación de (Castillo \& Rodríguez, 2016) se encontró una postura positiva ante el uso de las TIC en el salón de clase. El total de los docentes consideraron que el empleo de la tecnología en el aula sí beneficia el aprendizaje de los alumnos, es por esta razón que si hacen uso de los recursos tecnológicos de manera educativa, integrándolos como herramientas didácticas.

Cabe resaltar que en los resultados sobresale el aspecto de utilizar la tecnología para apoyarse de ella al dictar sus clases. (Bautista, Martinez, \& Hiracheta, 2014) aluden que con la Motivación, los materiales didácticos pueden también desarrollar las siguientes funciones. El desarrollo los temas en forma atractiva, interesante y comprensible y la facilitación, mediante procedimientos didácticos, que los estudiantes progresen exitosamente y puedan así conservar y acrecentar las expectativas iniciales. Las TIC como el video, multimedia, internet y equipo en general han servido de soporte en el proceso de enseñanza-aprendizaje y han sido realizando por los participantes con la finalidad de ayudar a mejorar la calidad de los procesos de enseñanza.

En relación al rechazo hacia una enseñanza tradicional, se menciona que el modelo de educación centrado en la enseñanza, se caracteriza por tener como protagonista al profesor y deja paso a un sistema basado en el aprendizaje, donde el alumno es el responsable de su propio proceso de aprendizaje y el profesor debe buscar y utilizar la metodología y los medios más adecuados que ayuden al alumno en ese proceso. García y Lacleta, (como se citó en (Bautista, Martinez, \& Hiracheta, 2014). Bajo esa mirada un curso enriquecido con materiales gráficos, diagramas, fotografías, presentaciones visuales, videos y mapas logra llamar más la atención de los estudiantes.

De esta manera se permite que el alumno forme parte implicándose en el proceso de aprendizaje, convirtiéndose en sujeto activo en vez de mero espectador. Esto trae como consecuencia que los alumnos se convierten en protagonistas. Se les da poder para buscar 
respuestas a sus preguntas, convirtiéndose el proceso de aprendizaje mucho más interesante para ellos (Alemañy, 2009).

Usar material didáctico es funcional dado que sirve para que los alumnos comprendan mejor el contenido que se quiere enseñar y para motivarlos en el momento del aprendizaje. Esto está relacionado al tipo de aprendizaje que se emplea hoy en día dejando de lado las clases magistrales y expositivas, centradas en el discurso del profesor, quien, de forma vertical y a veces dogmática, planteaba contenidos que no se contrastaban o eran enriquecidos por los alumnos de forma activa. Como menciona Ramírez (2008), las preocupaciones curriculares se centraban, casi exclusivamente, en la adquisición de conocimientos científico. Sin embargo, con la llegada de Internet en los años 90, la educación ha ido evolucionando, y se fue planteando la idea de diseñar un marco de referencia para la creación de los sistemas educativos desarrollados en la llamada sociedad de la información (citado en (Torres, 2010)

El uso que tiene la tecnología en la vida diaria de los estudiantes influye en los docentes a integrarlos en el dictado de sus clases. Debido a que piensa que al no utilizar la tecnología el alumno se puede aburrir, ya que esta tan acostumbrado a ese tipo de estímulos. Para (Bautista, Martinez, \& Hiracheta, 2014) los materiales didácticos favorecen a generar expectativas en los estudiantes sobre lo que van aprender, que los impulsa a trabajar por el logro de los objetivos.

En la investigación de (Chumpitaz| \& Rivero, 2012), se considera que las TIC apoyan el proceso de enseñanza - aprendizaje porque enriquecen de forma muy significativa la experiencia educativa. Los docentes no pueden ser ajenos a las características de los tiempos actuales, en los que el alumnado tiene mucha cercanía con el mundo tecnológico. En este sentido, la preparación y el uso de PPTs conectan a los docentes con el mundo de las TIC.

(Bautista, Martinez, \& Hiracheta, 2014) hacen referencia a que se deben utilizar materiales didácticos presentados mediante las herramientas tecnológicas que son de uso común para los estudiantes, estos materiales deben ser bien pensados en su elaboración especialmente para enseñar y aprender de manera que capten la atención de los estudiantes. Permitiendo que mediante estos materiales lleguen a adquirir los conceptos deseados y contribuir así al desarrollo de su pensamiento lógico al mismo tiempo que se sientan motivados con su aprendizaje.

Como mencionan (García, Portillo, Romo, \& Benito , 2007) García, Portillo, Romo y Benito (2007), ante el contexto en el que se encuentran los docentes en la 
actualidad, los inmigrantes deben adaptarse al medio. Lo cual significa, aprender a enseñar de una manera diferente y más atractiva, optado por tener más apertura y considerar esos nuevos lenguajes derivados del uso de los ordenadores, Internet y los videojuegos.

En esta línea, la investigación de (Chumpitaz| \& Rivero, 2012), menciona que la mayoría de los participantes utilizan herramientas tecnológicas en sus clases, siendo la computadora el medio principal para trasmitir la información. En relación a los resultados de la presente investigación, los docentes hacen uso de la tecnología y tienen una actitud favorable hacia ella. Éstos utilizan frecuentemente la laptop y écram ya que son los recursos más necesarios para el dictado de las clases y para su elaboración.

Morales, Moya y Rebolloso (1994) mencionan que, en la probabilidad de ejecución de un comportamiento concreto, se debe tener en cuenta el tipo de conducta, el objeto hacia el cual se dirige la misma, el lugar donde se lleva a cabo y el momento en el que transcurre la acción (citados en (Carpi \& Breva, 2001).

En este sentido, es importante señalar que, para el dictado de las clases, el colegio, brinda algunas herramientas tecnológicas para el dictado de las clases, como el préstamo de laptops. Es posible que, al tener las herramientas a su alcance y al estar en una institución que poco a poco implementa la tecnología en la enseñanza, siguiendo los hallazgos de Morales, Moya y Rebolloso, los profesores se sientan invitados a usar todos estos recursos tecnológicos en su trabajo pedagógico.

Es importante que el docente deba crear y buscar continuamente nuevas ideas y estrategias de intervención e instrumentos de enseñanza que ayuden a los alumnos a potenciar sus posibilidades. La inserción del uso de las TIC en las aulas permite nuevas formas de acceder, generar y transmitir información y conocimientos, teniendo como beneficio el poder ajustar no solo el tiempo, sino el espacio en el que se desarrolla la acción educativa (Bautista, Martinez, \& Hiracheta, 2014).

Kozma, $(2011,2012)$ menciona que el proceso en el que los centros educativos abandonan las prácticas tradicionales para migrar hacia las tecnológicas y potenciar estas herramientas al servicio de una nueva concepción del proceso de enseñanza educativa adaptada a las exigencias que se presentan en la actualidad, no es un automatismo que funciona con poner a disposición estas tecnologías en el aula (citado en (Mominó \& Sigales, 2017)

Para (Bautista, Martinez, \& Hiracheta, 2014) los materiales didácticos apoyan el aprendizaje de los estudiantes y el aumento de su éxito, por eso su importancia, porque 
pueden aumentar el logro estudiantil. Por ejemplo un tema realizado en una diapositiva puede proporcionar al alumno la oportunidad de practicar lo adquirido dentro de la clase, permitiéndole al estudiante explorar de forma independiente el tema ya enseñado. Lo óptimo es que los materiales didácticos utilizados para la enseñanza se ajusten al contenido de la clase del profesor. Por esta razón es tan importante que los docentes busquen la manera más adecuada de presentar sus materiales. Tomando en cuenta que el aprendizaje se dé por medio de una manera divertida.

(Chumpitaz| \& Rivero, 2012), confirman esta evidencia en uno de sus estudios y mencionan que los docentes utilizan herramientas como el PowerPoint, Excel, Word, etc. en sus clases a través del proyector, la multimedia y la computadora para pasar diapositivas o videos. Al igual que docentes de la presente investigación utilizan el PowerPoint para crear las sesiones presentadas en clase utilizando información buscada en la web.

Existen participantes que para mostrar sus diapositivas en el salón de clases se toman el tiempo para su adecuada elaboración. Incluyen materiales que a sus alumnos les va a interesar como imágenes o videos, información adicional que no está en el libro darle prioridad a las imágenes que al texto. (Celaya, Lozano, \& Ramírez, 2010) concluyeron en su investigación, que los profesores utilizan recursos electrónicos abiertos (de disponibilidad gratuita en Internet) para elegir materiales apropiados y usarlos en sus presentaciones. Sus resultados muestran que los docentes en algunos casos, toman en cuenta su plan de clase como guía, y sobre la base de éste, recurren a dichos recursos electrónicos para diseñar actividades de motivación o introducción al tema central que van a abordar. 


\section{Capítulo 5. CONCLUSIONES Y RELEVANCIA}

Como conclusión general de la presente investigación se halló que, de manera general, existe una actitud positiva hacia las TIC por parte de los docentes participantes. Sin embargo, es importante tener en cuenta que a nivel especifico se obtuvieron dos actitudes generales cada una de ellas está conformada por categorías que en conjunto conforman la actitud general. Cada categoría ha sido analizada según las tres características de la actitud.

En cuanto a la actitud positiva entre los participantes en utilizar la tecnología durante el dictado de clases, está conformado por tres categorías que lo conforman. En relación a la motivación para los alumnos, se encontró que los docentes emplean la tecnología para poder interesar y agachar al estudiante a la explicación que se da en clases. Con ayuda del dinamismo de los videos, herramientas tecnologías y las diapositivas se buscan suficiente motivación que le permita interesarse en el tema y de esta manera captar y procesar los conocimientos.

La categoría relacionada a captar la atención de los alumnos, se encuentra estrechamente relacionada con la Motivación, sin embargo en esta los docentes refieren que tratan directamente de mantener al alumno interesado en el proceso de la explicación. Es por ello que utilizan herramientas dinámicas, que les permite interactuar con ellas, que tiene colores llamativos. Mencionan que es muy importante usar las TIC por el mismo hecho que los alumnos son digitales nativos, por lo que la tecnología es parte de su vida diaria y se encuentra con facilidad en el entorno.

La última categoría, es el uso de las TIC en el desarrollo de las clases. Todos los docentes elaboran sus materiales e incluyen herramientas tecnologías, no siempre usan las diapositivas en ocasiones solo utilizan videos para abrir el tema y posteriormente siguen con material concreto, otros si elaborar dispositivas y algunos usan páginas interactivas.

En segundo lugar se halló la actitud de buena disposición hacia las TIC para elaborar el dictado de clases, este tema principal también está conformado por tres categorías que lo componen.

Relacionado al material guía para el dictado, se encontró entre las manifestaciones que la razón por la que emplean solo las diapositivas es para tener una secuencia al 
momento de dictar sus clases o para apoyarse visualmente al momento del dictado, de esta manera las dispositivas son una guía que le da secuencia y apoyo a sus explicaciones, porque les permite organizar sus ideas para transmitirlas claramente. Por otro lado se descubrió que algunos de los docentes que si utilizan la computadora y el proyector, no confiaban en la conexión con el internet, de esta manera utilizaban dispositivos USB para poder trasladar la información que querían mostrar a sus alumnos. Esta acción significaba en algunas ocasiones descargar videos de internet para posteriormente grabarlos en sus dispositivos.

En la categoría de integración de información adicional, en este aspecto los docentes usan la tecnología para agregar información adicional en su dictado de clases. Información adicional significa material que no se encuentra en los libros que utilizan. De esta manera le dan nuevo material o complementan con el que ya tienen. Un aspecto que surgió en una participante al momento de elaborar sus diapositivas es el de repasar sobre el tema antes del dictado de las clases. Otro docente incorporaba para su dictado de clases el uso de videos tomando en cuenta las características de sus alumnos y revisando si el contenido es el adecuado.

Para finalizar se tiene a la categoría de gestión de tiempo, algunos docentes lo asociaron a la economía en el tiempo para que elaborar su material ahora virtual versus al material concreto con el que trabajan cuando no había tecnología o como les enseñaron en la universidad. Comentando que la cantidad de moras empleadas frente a una computadora es menor. Por otro lado una docente menciona la economía del tiempo para el dictado de clases utilizando información precisa he imágenes que le permitan más dialogar y dictar el curso que le permite aclarar las dudas en vez de hacer explicaciones largas.

No existen estudios cualitativos en el ámbito nacional que aborden la actitud del docente frente a las TIC como herramienta de enseñanza. Por ello, la presente investigación es importante, porque aporta una información distinta al ser de carácter cualitativo, puede promover la realización de nuevos estudios en el ámbito educativo, no solo en colegios privados, sino también en centros de estudios superiores públicos o privados, que utilizan las TIC en su estrategia educativa.

Asimismo, el presente estudio evidencia que los beneficiarios de las prácticas docentes son los estudiantes, quienes se ven favorecidos con un proceso de aprendizaje más interactivo en el que se toman en cuenta sus opiniones. Gracias a las TIC, la clase 
está dirigida con herramientas amigables para su motivación y para fomentar su participación.

Del estudio se puede deducir que los participantes valoran el acceso a la información de manera sencilla y se preocupan por utilizar herramientas acorde al tema y al público al que va dirigido.

En general los participantes que muestran una actitud interesada o proactiva frente a las TIC para fines de la enseñanza y el aprendizaje, tienen claro que las usan como un medio para motivar a sus alumnos con el objetivo de que estos capten mayor importación y la enseñanza sea significativa. 


\section{Capítulo 6. LIMITACIONES Y RECOMENDACIONES}

Es importante señalar que esta investigación concentra sus resultados solo para los docentes que enseñan en un colegio particular de clase media baja, pero no abarcan a docentes de otros colegios. Por lo que los hallazgos encontrados solo se pueden circunscribir a los participantes del presente estudio ya que el propósito no es generalizar los hallazgos encontrados, sino profundizar el cocimiento sobre las particularidades de este grupo humano.

En relación a los docentes seleccionados se vio como una imitación hacer el estudio solo en docentes que usan tecnología para el dictado de clases, sería interesante e innovador saber cuáles son los resultados al entrevistar a docentes a nivel general frente a su actitud hacia tecnología como herramienta educativa. Así mismo el objetivo no es hacer un análisis de género ya que no se cuenta con la cantidad de participantes del género femenino para poder ahondar en el tema.

En relación a los temas tratados en la entrevista que se tuvo con cada participante, se pudo notar que les era difícil expresar la valoración de sus valoraciones por lo que se logró recolectar información limitada en este aspecto, es posible que el tener una sola entrevista con cada docente, no haya sido suficiente para profundizar en este aspecto.

El estudio, finalmente, solo utilizó la entrevista como técnica de recolección de información. Hubiera sido útil incluir la observación como un instrumento de recusación de información durante el dictado de clase. Esto habría permitido triangular la información y generar un insumo que enriqueciera la sección de discusión y resultados.

Finalmente estudios como éste, pueden derivar en nuevas investigaciones cuantitativas que abarquen a una mayor población de distintas facultades. Dados los hallazgos, esto parece ser necesario, y podría motivar al colegio a implementar herramientas periódicas de retroalimentación para conocer las actitudes de los docentes frente a la metodología y recursos que brinda la institución.

\section{REFERENCIAS}


Alemañy, C. (2009). Un nuevo rol docente en la era de las nuevas tecnologías. Eumed.net,, 1 (1).

Almerich, C., Suárez, R., \& Jornet, M. (2011). Las competencias y el uso de las tecnologías de información y comunicación (TIC) por el profesorado: estructura dimensional. (Vol. 13). Revista Electrónica de Investigación Educativa.

Aznar, D. I., Cáceres, M. P., \& Hinojo, L. F. (2005). El impacto de las TIC en la sociedad del milenio: nuevas exigencias de los sistemas educativos ante la alfabetización tecnológica.

(http://www.cursosdred.es/php/cursos/sc_formador_formadores/modulo3/unidad 1/ampliar/ELIMPACTO_delas_tic.pdf ed.). Ética Net.

Baelo, A., \& Cantón, M. (2009). Las tecnologías de la información y la comunicación en la educación superior. Revista Iberoamericana de Educación, , 1-12.

Bautista, S., Martinez, M., \& Hiracheta. (2014). El uso de material didáctico y las tecnologías de información y comunicación (TIC's) para mejorar el alcance académico. Ciencia y tecnología, 14, 83-194.

Braun, V., \& Clarke , V. (2006). Using thematic analysis in psychology. Qualitative Research in Psychology, 3(2), 77-101.

Cabero, A., \& Lorente, C. (2008). La alfabetización digital de los alumnos. Competencias digitales para el siglo XXI.

Carpi, B., \& Breva, A. (2001). La predicción de la conducta a través de los constructos que integran la teoría de acción planeada. Revista electrónica de motivación y emoción, 4(7).

Castillo, H., \& Rodríguez, G. (2016). La actitud del docente ante el uso de las TIC en su labor educativa. Revista Digital, 14.

Celaya, R., Lozano, M., \& Ramírez, M. (2010). Apropiación tecnológica en profesores que incorporan recursos educativos abiertos en educación media superior. Revista mexicana de investigación educativa, 15(45), 487-513.

Chumpitaz|, C., \& Rivero, P. (2012). Uso cotidiano y pedagógico de las TIC por profesores de una universidad privada de Lima. Revista de Educación.

Cornejo , M., \& Salas, N. (2011). Rigor y calidad metodológicos: un reto a la investigación social cualitativa. Psicoperspectivas, 10(2), 12-34.

Durán, M., \& Garces, L. (2015). Escúchame. El desafío del docente frente a las nuevas tecnologías 
(https://fido.palermo.edu/servicios_dyc/publicacionesdc/archivos/571_libro.pdf ed.). En Knop. F. Escritos en la Facultad N ${ }^{\circ} 109$.

educación, M. d. (2006). El proyecto Huascarán. El educador(7), 16-19.

Flores, M. (2012). Actitudes hacia las tecnologías de información y comunicación de los docentes de la red educativa $N^{\circ} 01$ Ventanilla-Callao.

García Arrea, S., \& Chikhani, A. (2012). Percepciones que tienen los docentes de américa latina sobre las tecnologías de la información y la comunicación.

García, F., Portillo, J., Romo, J., \& Benito , M. (2007). Nativos digitales y modelos de aprendizaje. In SPDECE.

Hernández, S., Fernández, C., \& Baptista, L. (2010). Metodología de la investigación. México: McGRAW-HILL.

López de la Madrid, M. (2007). Uso de las TIC en la educación superior de México (http://www.redalyc.org/articulo.oa?id=68800706 ed.). México: Apertura.

Lugo, M. (2010). Las políticas TIC en la educación de América Latina.

Marchesi, Á. (2012). Prenambulo. En R. Carneiro, J. Toscano, \& T. Díaz, Los desafios de las TIC para el cambio educativo (págs. 7-9). Madrid: OEI; Fundacion Santillana.

Marcone, F., Castro, K., Kanashiro, A., Núñez del Prado, B., \& León, O. (2010). Las TIC en la educación (http://www.cne.gob.pe/docs/cnepublicaciones/Las_TIC_en_la_educacion.pdf ed.).

Marquéz, G. (2000). La cultura de la sociedad de la información. Obtenido de http://www.peremarques.net/si.htm

Martínez, M. (2006). Ciencia y arte en la metodología cualitativa. México: Trillas.

Martínez, S. (2012). El muestreo en investigación cualitativa. Principios básicos y algunas controversias. Ciência \& Saúde Coletiva., 17(3), 613-619.

Mayan, M. (2001). An introduction to qualitative methods: a training module for students and professionals. [Una introducción a los métodos cualitativos: módulo de entrenamiento para estudiantes y profesionales. Obtenido de Qual Institute Press, International Institute for Qualitative Methodology: https://www.ualberta.ca/ iiqm/pdfs/introduccion.pdf

Mendizábal, N. (2006). Los componentes del diseño flexible en la investigación cualitativa. Barcelona: Gedisa.

Ministerio de Educación. (2013). Rutas de aprendizaje: Usa la ciencia y la tecnología para mejorar la calidad vida 
(http://www2.minedu.gob.pe/filesogecop/B\%2053574-

13\%20Caratula\%20Fasciculo\%20General\%20Ciencia_WEB.pdf ed.).

Mominó, J., \& Sigales, C. (2017). El impacto de las TIC en la educación. Más allá de las promesas. España, Cataluña: Universitat Oberta de Catalunya.

Montoro, G. J., Morales, M. G., \& Valenzuela, G. (2014). Competencias para el uso de tecnologías de la información y la comunicación en docentes de una escuela (http://aplicaciones.ccm.itesm.mx/virtualis/index.php/virtualis/article/view/91 ed., Vol. 5(9)). Virtualis.

Pacheco, F. (2002). Actitudes. Eúphoros.

Parra, G., \& Espinoza, S. (2016). El uso de redes sociales para fines académicos. Universidad Autónoma de Nayarit, Nayarit,, México.

Pérez, L., Lagos, L., Mardones, R., \& Sáez, F. (2018). Diseños de Investigación y Muestreo Cualitativo. Lo Complejo de Someter la Flexibilidad del Método Emergente a una Taxonomía Apriorística. Internacional de Comunicación.

Povera, R., \& Murillo, R. (2003). Las nuevas tecnologías en la enseñanza y aprendizaje de la matemática.

Prensky, M. (2010). El Talento de los Nativos Digitales. Madrid.

Romero, M., Saldívar, V., \& Delgado, I. (2011). Tecnologías de la información y la comunicación. México: Pearson Educación.

Romero, R. T. (2004). Las docentes y su relación con las nuevas tecnologías. Revista de Educación,.

Ruiz, F. P. (2002). Actitudes . Eúphoros, 173-186.

Sáez, L. (2010). Actitudes de los docentes respecto a las TIC, a partir del desarrollo de una práctica reflexiva; Sáez, L.J.M.

Sáez, L. J. (2010). Utilización de las TIC en el proceso de enseñanza aprendizaje, valorando la incidencia real de las tecnologías en la práctica docente. Revista Docencia e Investigación, 183-204.

Salomé, V. (2010). Uso de TIC en la práctica docente de los maestros de educación básica y bachillerato de la ciudad de Loja. EDUTEC. Revista electrónica de tecnología educativa, 3(33), 1-16.

Serbia, J. (2007). Diseño, muestreo y análisis en la investigación cualitativa. Hologramática.

Suárez, C. (29 de Junio de 2013). ¿Qué es la “Cultura Digital”? [Blog personal]. 
Tarrés, M. (2001). Observar, escuchar y comprender sobre la tradición cualitativa en la investigación social. México:: Facultad Latinoamericana de Ciencias Sociales.

Tejedor, T., \& García-Valcárcel, M. (2006). Competencias de los profesores para el uso de las TIC en la enseñanza Revista española de pedagogía, 64(233), 21-43.

Tejedor, T., Garcia Valcárcel, M., \& Prada, S. (2009). Medida de actitudes del profesorado universitario hacia la integración de las TIC.

Tello, D., \& Aguaded, G. (2009). Desarrollo profesional docente ante los nuevos retos de las tecnologías de la información y la comunicación en los centros educativos. (http://www.redalyc.org/articulo.oa?id=36812036003 ed., Vol. 34). Revista de Medios y Educación.

Torres, S. (2010). La enseñanza tradicional de las ciencias versus las nuevas tendencias educativas. Revista Electrónica Educare, 14(1), 131-142.

Universidad Peruana de Ciencias Aplicadas. (2014). La UPC continúa innovando e incorpora la tecnología de Apple en su proceso de aprendizaje. Obtenido de http://blogs.upc.edu.pe/noticias-upc/noticias/la-upc-continua-innovando-eincorpora-la-tecnologia-de-apple-en-su-proceso-de

Universidad Tecnológica del Perú (s/f). (s.f.). Promovemos la integración e las tecnologías para una mejor enseñanza. Obtenido de https://www.utp.edu.pe/servicios-universitarios/promovemos-integracion-lastecnologias-para-una-mejor-ensenanza

Valenzuela, A. (2013). Las redes sociales y su aplicación en la educación (http://www.revista.unam.mx/vol.14/num4/art36/art36.pdf ed., Vol. 14(4)). Revista digital universitaria.

Valverde, B. (2011). rofesorado, tecnología educativa e información didáctica. En Valverde, B.J. Docentes e-competentes, 13-26.

Viñals, B., \& Cuenca, A. (2016). El rol del docente en la era digital (Vol. 30). Revista Interuniversitaria de Formación del Profesorado. 


\section{APENDICE}

\section{Apéndice 1}

\section{Consentimiento informado}

Yo, con

DNI de años de edad, acepto de manera

voluntaria participar en una investigación sobre el uso de la tecnología en el aula de clases. La entrevista será grabada y realizada por María Fernanda Zamora, estudiante de psicología como parte de una investigación para la elaboración de Tesis. Las entrevistas grabadas servirán únicamente para los fines académicos de esta investigación, salvaguardando la identidad de la participante al no revelar la identidad en ningún momento de la investigación, ni después de ella.

Lima, de del 2017

Firma de la participante

Firma del investigador

Consentimiento informado

Yo, con DNI de años de edad, acepto de manera voluntaria participar en una investigación sobre el uso de la tecnología en el aula de clases. La entrevista será grabada y realizada por María Fernanda Zamora, estudiante de psicología como parte de una investigación para la elaboración de Tesis. Las entrevistas grabadas servirán únicamente para los fines académicos de esta investigación, salvaguardando la identidad de la participante al no revelar la identidad en ningún momento de la investigación, ni después de ella. Lima, de del 2017

Firma de la participante

Firma del investigador 


\section{Apéndice 2}

\section{Guía de entrevista}

Buenos días mi nombre es Maria Fernanda y estoy realizando una investigación para saber cuáles son las actitudes de los docentes frente a la tecnología de información y comunicación. Empezaremos con una pregunta y alrededor de esta iremos conversando. La entrevista será grabada para poder transcribirla posteriormente.

Me gustaría antes de comenzar que leamos el consentimiento informado junto y si tienes alguna duda me lo hagas saber.

¿En qué momento te apoyas de la tecnología?

Activación 1. ¿En qué momento de según las clases te apoyas contexto

- ¿Por qué en ese momento te sirve utilizar el material virtual o los ppts?

- ¿Utilizas estos materiales con frecuencia?

- ¿Con la ayuda de ellos logras el objetivo de tus clases?

Valor antagónico 2.¿Cómo valoras está tic en este contexto?

- ¿Cuánto crees que la tecnología ayuda al profesor a la enseñanza?

- ¿En qué momentos no te apoyas de la tecnología? ¿Por qué?

- ¿Qué aspectos negativos tiene?

- ¿Qué aspectos positivos tiene?

\begin{tabular}{|c|c|c|}
\hline $\begin{array}{l}\text { Opinión de } \\
\text { su } \\
\text { valoración }\end{array}$ & $\begin{array}{ll}\text { 3. ¿Qué opinas de } \\
\text { (mencionar } & \text { su } \\
\text { valoración acerca de } \\
\text { las TIC)? }\end{array}$ & \\
\hline $\begin{array}{l}\text { Activación } \\
\text { según } \\
\text { contexto }\end{array}$ & $\begin{array}{l}\text { 4. ¿Cómo es la } \\
\text { elaboración de tus } \\
\text { diapositivas? }\end{array}$ & $\begin{array}{l}\text { - ¿Utilizas información del libro o de la web? } \\
\text { - ¿Con cuántos días de anticipación los } \\
\text { elaboras? }\end{array}$ \\
\hline $\begin{array}{l}\text { Valor } \\
\text { antagónico }\end{array}$ & $\begin{array}{l}\text { 5. ¿Crees que es } \\
\text { necesario elaborar? }\end{array}$ & $\begin{array}{l}\text { - ¿Qué aspectos negativos tiene? } \\
\text { - ¿Qué aspectos positivos tiene? }\end{array}$ \\
\hline $\begin{array}{l}\text { Opinión de } \\
\text { su } \\
\text { valoración }\end{array}$ & $\begin{array}{l}\text { 6. ¿Qué opinas de } \\
\text { (mencionar } \\
\text { valoración acerca de } \\
\text { las TIC)? }\end{array}$ & \\
\hline
\end{tabular}

